OPEN ACCESS

Edited by:

Vincenzo Lionetti,

Sapienza University of Rome, Italy

Reviewed by:

Juan Carlos Díaz Ricci,

Universidad Nacional de Tucumán,

Argentina

Manuel Benedetti,

University of L'Aquila, Italy

*Correspondence:

Anna Maria Salzano

annamaria.salzano@cnr.it

Sheridan Lois Woo

woo@unina.it

${ }^{\dagger}$ These authors have contributed equally to this work

Specialty section: This article was submitted to Plant Microbe Interactions, a section of the journal

Frontiers in Microbiology

Received: 23 December 2019 Accepted: 27 May 2020

Published: 03 July 2020

Citation:

Lombardi N, Caira S, Troise $A D$,

Scaloni A, Vitaglione $P$, Vinale $F$, Marra R, Salzano AM, Lorito $M$ and Woo SL (2020) Trichoderma Applications on Strawberry Plants Modulate the Physiological Processes Positively Affecting Fruit Production and Quality

Front. Microbiol. 11:1364. doi: 10.3389/fmicb.2020.01364

\section{Trichoderma Applications on} Strawberry Plants Modulate the Physiological Processes Positively Affecting Fruit Production and Quality

\author{
Nadia Lombardi ${ }^{1+}$, Simonetta Caira ${ }^{2 t}$, Antonio Dario Troise ${ }^{1,2}$, Andrea Scaloni², \\ Paola Vitaglione', Francesco Vinale 3,4 , Roberta Marra ${ }^{1}$, Anna Maria Salzano ${ }^{2 *}$, \\ Matteo Lorito ${ }^{1,4,5}$ and Sheridan Lois Woo ${ }^{4,5,6 *}$
}

\begin{abstract}
'Department of Agricultural Sciences, University of Naples Federico II, Naples, Italy, ${ }^{2}$ Proteomics and Mass Spectrometry Laboratory, ISPAAM, National Research Council, Naples, Italy, ${ }^{3}$ Department of Veterinary Medicine and Animal Productions, University of Naples Federico II, Naples, Italy, ${ }^{4}$ Institute for Sustainable Plant Protection, National Research Council, Portici, Italy, ${ }^{5}$ Task Force on Microbiome Studies, University of Naples Federico II, Naples, Italy, ${ }^{6}$ Department of Pharmacy,

University of Naples Federico II, Naples, Italy
\end{abstract}

Many Trichoderma spp. are successful plant beneficial microbial inoculants due to their ability to act as biocontrol agents with direct antagonistic activities to phytopathogens, and as biostimulants capable of promoting plant growth. This work investigated the effects of treatments with three selected Trichoderma strains (T22, TH1, and GV41) to strawberry plants on the productivity, metabolites and proteome of the formed fruits. Trichoderma applications stimulated plant growth, increased strawberry fruit yield, and favored selective accumulation of anthocyanins and other antioxidants in red ripened fruits. Proteomic analysis of fruits harvested from the plants previously treated with Trichoderma demonstrated that the microbial inoculants highly affected the representation of proteins associated with responses to stress/external stimuli, nutrient uptake, protein metabolism, carbon/energy metabolism and secondary metabolism, also providing a possible explanation to the presence of specific metabolites in fruits. Bioinformatic analysis of these differential proteins revealed a central network of interacting molecular species, providing a rationale to the concomitant modulation of different plant physiological processes following the microbial inoculation. These findings indicated that the application of Trichoderma-based products exerts a positive impact on strawberry, integrating well with previous observations on the molecular mechanisms activated in roots and leaves of other tested plant species, demonstrating that the efficacy of using a biological approach with beneficial microbes on the maturing plant is also able to transfer advantages to the developing fruits.

Keywords: Fragaria $x$ ananassa, Trichoderma, proteomics, antioxidant, phenolics, anthocyanins

Abbreviations: ASA/DHA, ascorbic acid/dehydroascorbic acid ratio; BCAs, biological control agents; DRPs, differentially represented proteins; GSH/GSSG, reduced glutathione/oxidized glutathione ratio; MRM, multiple reaction monitoring; MS, mass spectrometry; MS/MS, tandem mass spectrometry; TMT, tandem mass tagging. 


\section{INTRODUCTION}

For centuries, the fruits of strawberry (Fragaria $x$ ananassa Duch.) have been consumed, appreciated for their taste and nutritional properties. Their cultivation has augmented in recent years, with productivity increasing to more than 9 million tons worldwide in 2017 (Food and Agriculture Organization of the United Nations, 2018) ${ }^{1}$. Human health benefits derived from eating strawberry fruits include heart protection, reduced blood pressure, as well as anticancer and anti-inflammatory activities (Liu et al., 2000; Joseph et al., 2014). These effects are related to the high content of phenolic compounds, vitamin C, anthocyanins, proanthocyanidins (cyanidin and pelargonidin derivatives) and other antioxidants, which contrast oxidative stress and retard cellular aging (Hanhineva et al., 2011; Giampieri et al., 2012; Joseph et al., 2014; Park et al., 2017). Anthocyanins represent the main flavonoid class in strawberry fruits that play an active role in the determination of the red pigmentation and in the evaluation of fruit ripeness (da Silva et al., 2007). Ripened strawberries contain high concentrations of pelargonidin glycosides, including pelargonidin 3-O-glucoside, pelargonidin 3-O-malonyl-glucoside, pelargonidin 3-O-rutinoside and cyanidin 3-O-glucoside, which may represent up to 95,33 , 7 , and $6 \%$, respectively, of the total anthocyanins (Aaby and Remberg, 2015). Previous studies reported that the biosynthesis of antioxidant metabolites (and the corresponding concentration in the fruit) is strongly influenced by the interaction of the plant genotype and cultivation practices, i.e., fertilization, with the growth environment (Anttonen et al., 2006; Buendia et al., 2010; Aaby et al., 2012). The metabolomic dynamics are also affected by the nutritional status of the plant, as noted with iron- and phosphorus- deficiencies in the rhizosphere, often compensated by the regulation of root exudates that influence nutrient bioavailability and uptake determining fruit quality (Valentinuzzi et al., 2015). Furthermore, metabolite composition of strawberry are also associated with the phenology of the plant, developmental stages of the fruit, vegetative structure and interactions with biotic and abiotic stress factors that correspond to plant responses to the pathogen/pest attack and to adverse factors in the environment (Hanhineva et al., 2011).

Recent findings reinforce the concept that some microbial biological control agents (BCAs) may have multiple beneficial effects on plants, that not only include disease control, but also the stimulation of plant growth, increased yield, enhanced bioavailability and uptake of nutrients, as well as improvement of crop quality (Pascale et al., 2017; Woo and Pepe, 2018; Marra et al., 2019). Numerous fungi belonging to the genus Trichoderma have been widely studied as BCAs for their antagonistic and plant biostimulant activities; they are present as active ingredients in more than 200 products marketed worldwide as biofungicides, biofertilizers, biostimulants, and soil probiotics for agriculture (Woo et al., 2014). Furthermore, many Trichoderma spp. applied as biofungicides and considered as alternatives to chemical phytosanitary products of synthesis, are proven efficient antagonists of many causal disease agents of

${ }^{1}$ www.fao.org strawberry such as Botrytis or Colletotrichum (Tronsmo and Dennis, 1977; Freeman et al., 2004; Porras et al., 2007).

Several Trichoderma strains are endophytes able to establish a complex molecular crosstalk network in interactions with other rhizosphere microorganisms and the plant, which improve plant feedback to different stresses, and the ability to improve crop development and productivity (Vinale et al., 2008; Hermosa et al., 2012; Lombardi et al., 2018).

Since the early observations of the plant growth promotion effects by Trichoderma treatments to the plant (Baker, 1988; Klefield and Chet, 1992; Ousley et al., 1994), investigations in this field of research have been steadily intensified in an attempt to understand the mechanisms involved. Root colonization by Trichoderma spp. was found to be associated with enhanced plant nutrient uptake as result of an improved efficient solubilization of macro- and micro-nutrients (Altomare et al., 1999; Yedidia et al., 2001; de Santiago et al., 2011) that modified the metabolism of several crops (Harman, 2004; Vinale et al., 2008, 2012; Hermosa et al., 2012). Modern technologies in the "omics" era permitted functional studies on the beneficial fungus (Lorito et al., 2010), the host plant (Harman et al., 2004a), as well as on the interactions between Trichoderma, plant and pathogens (Marra et al., 2006). Proteomic and transcriptomic approaches were used to characterize metabolic pathways and molecular processes underlying the plant response to treatments with Trichoderma preparations, specifically regarding the plant defense responses (Yedidia et al., 2000) and induced systemic resistance (Shoresh et al., 2010). The various studies that described the plant responses to these beneficial microbes were performed on root and leaf tissues obtained from diverse plant species, i.e., bean, maize, tomato, cucumber and grapevine. These plants were treated with $T$. harzianum or $T$. virens in order to evaluate the differential quantitative changes in proteins/genes related to specific signaling cascades and metabolic pathways involved in defense responses, redox stresses and carbon/energy metabolism (Marra et al., 2006; Segarra et al., 2007; Shoresh and Harman, 2008; Perazzolli et al., 2016; Manganiello et al., 2018; Nogueira-Lopez et al., 2018; De Palma et al., 2019). Although proteomics and metabolomics have found a large application in the characterization of the physiological changes occurring during development, ripening and post-harvest of diverse fruits (Guarino et al., 2007; D'Ambrosio et al., 2013; Molassiotis et al., 2013; Salzano et al., 2018, 2019), including strawberry (Bianco et al., 2009; Li et al., 2013, 2015), the objectives have been largely focused on the quality of the harvested products and the effects of conservation conditions.

The principle method to administer the biological products containing Trichoderma in agricultural production is by direct applications to the seed or the developing plant (Woo et al., 2014), and any positive changes noted by the treatments are observed on the growing plant (biomass) and the developing fruit, which are reflected in the biometric parameters important for evaluating yield quantity. However, only a very few reports have provided information on specific genes or enzymatic activities in the fruits, when the corresponding plants have been inoculated with $T$. harzianum preparations; the only case is for tomato (Chacón et al., 2007; Singh et al., 2018). No dedicated investigations have 
been performed on fruits collected from plants treated with microbial BCAs in order to evaluate the metabolic pathways and molecular changes that can influence the quality and beneficial health characteristics in the harvested products.

To investigate the outcome of Trichoderma on strawberry, in particular on the fruit, this study was undertaken to determine the effects of treatments with different Trichoderma strains on the productivity of strawberry, on the plant growth promotion of above/below ground vegetative structures, and the reproductive structures determining fruit yield. Moreover, multiple approaches assayed the physiological characteristics of strawberry after the application of these beneficial fungi to the mother plant, which could have an effect on the corresponding formed fruits, anthocyanin and antioxidant compound content, and the representation of proteins associated with signaling, energetic and metabolic processes, as well as with plant response to biotic/abiotic stresses. This study provides evidences that Trichoderma can have positive effects on above-mentioned plant physiological parameters, as well as on beneficial compounds that highly influence food quality and consumer health.

\section{MATERIALS AND METHODS}

\section{Fungal Strains}

Trichoderma harzianum strains $\mathrm{T} 22$ and $\mathrm{TH} 1$, and $T$. virens strain GV41 were obtained from a microbial collection available at the Department of Agricultural Sciences of the University of Naples Federico II, Portici, Italy, and cultivated bimonthly on Potato Dextrose Agar (HI-MEDIA, Pvt. Ltd., Mumbai, India), at $25^{\circ} \mathrm{C}$. Trichoderma propagules were produced by solid-state fermentation on sterile rice bran $(500 \mathrm{~g})$ inoculated with a spore suspension $\left(1 \times 10^{6}\right.$ spores $\left./ \mathrm{mL}\right)$, and incubated at $25^{\circ} \mathrm{C}$. After 7 days, the spores were collected washing the rice bran with sterile water. Spore suspensions were adjusted to the desired concentration by using a haemocytometer. T. harzianum strain $\mathrm{T}-22$ and $T$. virens strain G-41 (GV41) are registered mBCA Plant Protection Products, components biofungicides on the agricultural market that meet safety criteria established by EPA and EU governing bodies. T. harzianum strain TH1 does not produce noted toxic compounds as determined by metabolomic analysis (Vinale and Woo, data not shown).

\section{Plant Material, Treatments and Sampling}

Experiments were carried out in the greenhouse at the Department of Agricultural Sciences of the University of Naples Federico II, Portici, Italy, under natural, seasonal environmental conditions. Fresh transplants of uniform size of Fragaria $x$ ananassa cv. Sabrina were transplanted in October 2016 into $25 \mathrm{~cm}$-diameter pots (one plant per pot) filled with sterile soil. The trial was arranged in a completely randomized block design with 2 biological replicates per treatment and 10 plants in each replicate. Fungal spore suspensions (T22, TH1, and GV41) were tested at $10^{7}$ spores $/ \mathrm{mL}$ in water. They were applied once by root dip (15 min) immediately prior to transplanting, and monthly by irrigation $(25 \mathrm{~mL})$ until 7 days before the first harvest. Controls consisted in water-treated plants (CTR). Throughout the duration of the field experiment, the disease incidence of the most common strawberry pathogens was monitored on plants and fruits.

Ripe fruits were harvested at the commercial stage from Trichoderma-treated and control plants once per week from April to June 2017 and individually counted and weighed. All strawberry plants were harvested at the end of June 2017, and thoroughly washed under running tap water to remove soil particles. Plants were dried in oven at $65^{\circ} \mathrm{C}$ for about $72 \mathrm{~h}$, until achieving a constant weight. For each treatment, total yield (TY), number of fruits/plant (NF), root length (RL), root fresh weight (RFW), and root dry weight (RDW) were measured.

\section{Preparation of Fruit Samples for Chemical and Proteomic Analyses}

Red ripe fruits from Trichoderma-treated and control plants were immediately ground in liquid $\mathrm{N}_{2}$ and stored at $-80^{\circ} \mathrm{C}$ until their use. For chemical analyses, individual freeze-dried strawberries were stored in a desiccator, at room temperature, in the dark, and then pulverized by using a knife mill Grindomix GM 200 (Retsch, Haan, Germany). Powdered strawberry samples were pooled according to treatment and used for further chemical analyses.

For proteomic analysis, individual frozen strawberries were pooled according to treatment, grounded in a blender and finally grinded in a mortar, using copious liquid $\mathrm{N}_{2}$ to avoid tissue defrosting. Samples were then lyophilized, and immediately processed for further proteomic analysis.

\section{Determination of Total Antioxidant Capacity and Total Phenolic Content in Fruits}

The 2,2-diphenyl-1-picrylhydrazyl (DPPH) free radical assay was used to measure total antioxidant capacity (TAC) of strawberry fruit hydroalcoholic extracts (Sharma and Bhat, 2009). Briefly, $1 \mathrm{~mL}$ of a solution $1 \% \mathrm{v} / \mathrm{v}$ formic acid in methanol:water $(70: 30 \mathrm{v} / \mathrm{v})$ was added to $10 \mathrm{mg}$ of each sample, which was then homogenized; the suspension was vortexed and then centrifuged $\left(14800 \mathrm{rpm}, 4^{\circ} \mathrm{C}\right.$, for $\left.10 \mathrm{~min}\right)$. DPPH was dissolved in methanol $(0.4 \mathrm{mg} / \mathrm{mL})$ and the absorbance at a wavelength of $517 \mathrm{~nm}$ was adjusted to $0.9 \pm 0.02$ by using a T92+ UV double beam spectrophotometer (PG Instruments, Leicester, United Kingdom). Scavenging capacity was evaluated by dissolving $0.2 \mathrm{~mL}$ of each hydroalcoholic extract in $0.9 \mathrm{~mL}$ of $\mathrm{DPPH}$ solution; after incubation at $25^{\circ} \mathrm{C}$, for $10 \mathrm{~min}$, the absorbance was measured at $517 \mathrm{~nm}$. Percentage of inhibition was calculated with respect to a solution of $1 \% \mathrm{v} / \mathrm{v}$ formic acid in methanol:water $(70: 30 \mathrm{v} / \mathrm{v})$. A trolox calibration curve was built in the range 10-120 $\mu \mathrm{M}$, and TAC was expressed as $\mu \mathrm{mol}$ of trolox equivalent per gram of dry matter. Each extraction was performed in duplicate for a whole of eight observations for each sample.

Total phenolic content (TPC) was measured through the colorimetric Folin-Ciocalteu method, following the procedure of Singleton et al. (1998). Gallic acid was used as a standard, and a series of calibration solutions was prepared in the concentration range $0.020-0.150 \mathrm{mg} / \mathrm{mL}$. Sample hydroalcoholic suspensions 
were prepared as described above. A $0.1 \mathrm{~mL}$ sample aliquot was mixed with $0.5 \mathrm{~mL}$ of distilled water and $125 \mu \mathrm{L}$ of FolinCiocalteu solution. The mixture was vortexed $(1000 \mathrm{rpm})$, left for $6 \mathrm{~min}$ at room temperature and added with $1.25 \mathrm{~mL}$ of 0.70 $\mathrm{M}$ sodium carbonate. The mixture was vigorously vortexed and incubated for $90 \mathrm{~min}$, at room temperature. The absorbance of samples was measured at $760 \mathrm{~nm}$.

\section{Determination of Ascorbic Acid Content in Fruits}

Strawberry samples (500 mg) were extracted with $5 \mathrm{~mL}$ of an aqueous solution containing 3\% v/v metaphosphoric acid and $8 \%$ $\mathrm{v} / \mathrm{v}$ acetic acid. Upon vortexing and centrifugation (4000 rpm, at $4^{\circ} \mathrm{C}$, for $10 \mathrm{~min}$ ), acid extracts were titrated using an indophenol solution (25\% w/v 2,6-dichloroindophenol, $21 \% \mathrm{w} / \mathrm{v} \mathrm{NaHCO}_{3}$ ), until a light pink color appeared. Different concentrations of ascorbic acid were titrated with above-mentioned indophenol solution in order to build up a standard calibration curve (Ramirez et al., 1996).

\section{Analysis of Anthocyanins in Fruits by LC-DAD-ESI-MS/MS}

Samples were extracted according to Holzwarth et al. (2012), with minor modifications. Strawberry dried samples $(50 \mathrm{mg})$ were suspended in $3 \mathrm{~mL}$ of $5 \% \mathrm{v} / \mathrm{v}$ formic acid in methanol, sonicated for $10 \mathrm{~min}$, at $40^{\circ} \mathrm{C}$, and finally placed in a water bath $\left(40^{\circ} \mathrm{C}\right)$, under agitation. Samples were centrifuged $(4000 \mathrm{rpm}$, at $4^{\circ} \mathrm{C}$, for $10 \mathrm{~min}$ ), and $1 \mathrm{~mL}$ of each supernatant was dried at $40^{\circ} \mathrm{C}$ in a Savant centrifugal evaporator (Thermo-Fisher, Bremen, Germany). Dried extracts were dissolved in $0.3 \mathrm{~mL}$ of $5 \% \mathrm{v} / \mathrm{v}$ formic acid, filtered with modified cellulose filters $(0.22 \mu \mathrm{m}$, Phenomenex, Torrance, CA, United States), and $10 \mu \mathrm{L}$ of each solution was injected into the LC system. Quantitative analysis of anthocyanins was performed by using a Shimadzu LC10AD binary system (Shimadzu, Kyoto, Japan) equipped with a SPDM10A diode array detector (DAD, Shimadzu) and a Series 200 autosampler (Perkin Elmer, Billerica, MA, United States). Chromatographic separation was achieved through a Kinetex XB-C18 column $(150 \times 4.6 \mathrm{~mm}, 5 \mu \mathrm{m}, 100 \AA$, Phenomenex $)$ equipped with a C18 ODS guard column $(4.0 \times 3.0 \mathrm{~mm})$, at $25^{\circ} \mathrm{C}$, with a flow rate of $0.8 \mathrm{~mL} / \mathrm{min}$. Mobile phase A was $5 \% \mathrm{v} / \mathrm{v}$ formic acid and mobile phase $\mathrm{B}$ was $5 \% \mathrm{v} / \mathrm{v}$ formic acid in methanol. The following binary gradient $(\mathrm{min} / \% \mathrm{~B})$ was used: $(0 / 20),(3 / 20)$, (15/55), (18/55), (22/90), (25/90). Typical benzopyrylium and flavylium ions of anthocyanins were monitored at $520 \mathrm{~nm}$.

For peak assignment, samples were injected into an API2000 triple quadrupole tandem mass spectrometer (AB Sciex, Carlsbad, CA, United States) by using the same chromatographic conditions listed above. Positive electrospray ionization was used for the detection; source parameters were as follows: spray voltage $5.5 \mathrm{kV}$; capillary temperature $300^{\circ} \mathrm{C}$, dwell time $100 \mathrm{~ms}$. The chromatographic profile was recorded in multiple reaction monitoring mode (MRM). Tentative identification of individual anthocyanins was achieved according to Määttä-Riihinen et al. (2004) by using mass transitions given in parentheses: cyanidin 3-O-glucoside $(\mathrm{m} / \mathrm{z}$
$449 \rightarrow 287)$, pelargonidin 3-O-glucoside $(m / z 433 \rightarrow 271)$, pelargonidin 3-O-rutinoside $(\mathrm{m} / \mathrm{z} 579 \rightarrow 271)$, pelargonidin 3-O-malonyl-glucoside $(\mathrm{m} / \mathrm{z} 519 \rightarrow 271)$, pelargonidin 3-Oacetyl-glucoside $(\mathrm{m} / \mathrm{z} 475 \rightarrow 271)$ and cyanidin derivative $(\mathrm{m} / \mathrm{z} 449 \rightarrow 287)$. Individual anthocyanins were quantified using calibration curves of pelargonidin 3-O-glucoside, while cyanidin was used for the quantification of anthocyanidins (aglycone form). Three sets of calibration curves were built in the range $0.1-50 \mu \mathrm{g} / \mathrm{mL}$ according to the limit of detection and the limit of quantitation (Armbruster and Pry, 2008). Three replicates of the solutions $50 \mathrm{ng} / \mathrm{mL}$ were injected into the LC-DAD system to verify the lowest concentration for which the signal to noise ratio was higher than three. The $r^{2}$ value was calculated plotting the area counts against the injected concentrations. Each point of the calibration curves was injected three times in the same day (intraday assay for the repeatability) and three times in three different days (interday assay for the reproducibility); the accuracy was reported as the discrepancies between nine calibration curves performed intraday and interday. Slope among the calibration curves was calculated and compared to each point of each calibration curve. Results were expressed as relative standard deviation (\%). Each sample was extracted and injected twice for a total of 4 observations; results were reported as $\mu \mathrm{g} / \mathrm{g}$ of fruit sample. In case of lacking standards, the calibration of structurally related compounds was used and corrected by a molecular weight factor (Chandra et al., 2001).

\section{Fruit Protein Extraction, Digestion and Peptide Fractionation}

Lyophilized samples from pooled frozen fruits of Trichodermatreated and control strawberry plants (9 fruits collected from 3 plants for each condition) were quickly extracted in parallel for proteins through a slightly modified phenolextraction method followed by ammonium acetate-methanol precipitation (Li et al., 2015). Thus, $1 \mathrm{~g}$ of lyophilized powder of each sample was mixed in a mortar with $1 \% \mathrm{w} / \mathrm{w}$ polyvinylpyrrolidone, and resuspended in $10 \mathrm{~mL}$ of $0.7 \mathrm{M}$ sucrose, $0.1 \mathrm{M} \mathrm{KCl}, 0.5 \mathrm{M}$ Tris- $\mathrm{HCl}, 50 \mathrm{mM}$ EDTA, $40 \mathrm{mM}$ DTT, $\mathrm{pH} 8.5$, containing a protease inhibitors cocktail for plant tissues (Sigma-Aldrich, United States). Homogenization was performed in an Ultra-Turrax tissue processor (IKA, Werke GmbH, Germany) for $1 \mathrm{~min}$, at $6000 \mathrm{rpm}$. Trisbuffered phenol, $\mathrm{pH} 8.0$ (Sigma-Aldrich) was added to the suspension $(1: 1, \mathrm{v} / \mathrm{v})$ and the sample was mixed thoroughly and centrifuged at $10,000 \times g$, for $15 \mathrm{~min}$, at $4^{\circ} \mathrm{C}$. The extraction was repeated twice and phenol phases were collected and precipitated with $5 \mathrm{vol}$ of cold $0.1 \mathrm{M}$ ammonium acetate in methanol, at $-20^{\circ} \mathrm{C}$, overnight. Protein pellets were washed twice with ice-cold methanol and finally with cold acetone containing $20 \mathrm{mM} \mathrm{DTT}$, and then air-dried. Protein pellets (5 mg) were solubilized in $250 \mu \mathrm{L}$ of $7 \mathrm{M}$ urea, $2 \mathrm{M}$ thiourea, $50 \mathrm{mM}$ triethylammonium bicarbonate (TEAB), 2\% SDS, $10 \mathrm{mM}$ DTT, pH 8.5, and added with plant specific protease inhibitors (Sigma-Aldrich). Samples were vortexed and incubated for $1 \mathrm{~h}$, at $30^{\circ} \mathrm{C}$, under shaking. Samples were 
centrifuged at $12,000 \times g$ for $5 \mathrm{~min}$, at $5^{\circ} \mathrm{C}$, and the taken of the supernatant containing the corresponding protein extract. Protein concentration was determined using the Bio-Rad Protein Assay (Bio-Rad, Hercules, CA, United States), according to manufacturer's instructions. Relative quantification of individual proteins was obtained by a tandem mass tagging (TMT)labeling experiment using a TMT10plex Isobaric Label Reagent Kit (Thermo-Fisher Scientific, United States); protein samples were prepared according to manufacturer's instructions. Thus, an aliquot of each protein sample $(100 \mu \mathrm{g})$ was adjusted to a $100 \mu \mathrm{L}$ final volume with $100 \mathrm{mM} \mathrm{TEAB}$, and then treated as reported in the manufacturer's instructions. Each sample was digested with freshly prepared trypsin (enzyme to protein ratio $1: 50 \mathrm{w} / \mathrm{w}$ ) in $100 \mathrm{mM} \mathrm{TEAB}$, at $37^{\circ} \mathrm{C}$, overnight. Resulting peptides from each protein sample were labeled with the TMT10plex Label Reagent Set (ThermoFisher Scientific), at $25^{\circ} \mathrm{C}$, following manufacturer's instructions, according to the labeling scheme: Ctrl-TMT10-126, T22-2TMT10-127N, TH1-TMT10-127C, and GV41-TMT10-128N. After $1 \mathrm{~h}$ of reaction, $8 \mu \mathrm{L}$ of $5 \% \mathrm{w} / \mathrm{v}$ hydroxylamine was added in each tube and mixed for $15 \mathrm{~min}$, in order to quench the derivatization reaction. For a set of comparative experiments, tagged peptide mixtures were mixed in equalmolar ratios $(1: 1: 1: 1)$ and vacuum-dried under rotation. Then, pooled TMT-labeled peptide mixtures were suspended in $0.1 \% \mathrm{v} / \mathrm{v}$ trifluoroacetic acid, and fractionated by using the Pierce High $\mathrm{pH}$ Reversed-Phase Peptide fractionation kit (Thermo-Fisher Scientific) according to manufacturer's instructions. After fractionation, eight fractions of TMTlabeled peptides were collected, vacuum-dried and finally reconstituted in $0.1 \% \mathrm{v} / \mathrm{v}$ formic acid for subsequent mass spectrometric analysis.

\section{NanoLC-ESI-Q-Orbitrap MS/MS Analysis of Fruit Protein Digests}

Tandem mass tagging-labeled peptide fractions were analyzed with a nanoLC-ESI-Q-Orbitrap-MS/MS platform consisting of an UltiMate 3000 HPLC RSLC nano system (Dionex, United States) coupled to a Q Exactive Plus mass spectrometer through a Nanoflex ion source (Thermo-Fisher Scientific). Peptides were loaded on an Acclaim PepMap RSLC C18 column $(150 \mathrm{~mm} \times 75 \mu \mathrm{m}$ ID, $2 \mu \mathrm{m}$ particles, $100 \AA$ pore size, Thermo-Fisher Scientific), and eluted with a gradient of solvent B (19.92/80/0.08 v/v/v water/acetonitrile/formic acid) in solvent A (99.9/0.1 v/v water/formic acid), at a flow rate of $300 \mathrm{~nL} / \mathrm{min}$. The gradient of solvent $\mathrm{B}$ started at $5 \%$, increased to $60 \%$ over $125 \mathrm{~min}$, raised to $95 \%$ over $1 \mathrm{~min}$, remained at $95 \%$ for $8 \mathrm{~min}$. The mass spectrometer operated in data-dependent mode, using a full scan $(\mathrm{m} / \mathrm{z}$ range 375-1500, nominal resolution of 70,000), followed by MS/MS scans of the 10 most abundant ions. MS/MS spectra were acquired in a scan $\mathrm{m} / z$ range $110-2000$, using a normalized collision energy of $32 \%$, an automatic gain control target of 100,000, a maximum ion target of $120 \mathrm{~ms}$, and a resolution of 17,500. A dynamic exclusion value of $30 \mathrm{~s}$ was also used.

\section{Bioinformatics for Protein Identification and Quantitation}

Raw data files were analyzed for protein identification and relative protein quantification with Proteome Discoverer v. 2.1 software (Thermo Scientific), enabling the database search by Mascot algorithm v. 2.6 (Matrix Science, United Kingdom) using the following criteria: NCBI protein database (Viridiplantae, 6216064 protein sequences, 12/2018) including the most common protein contaminants; carbamidomethylation of Cys and TMT modification of lysine and peptide $\mathrm{N}$-terminal as fixed modifications; oxidation of Met, deamidation of Asn and Gln, pyroglutamate formation of Gln as variable modifications. Peptide mass tolerance was set to $\pm 10 \mathrm{ppm}$ and fragment mass tolerance to $\pm 0.02 \mathrm{Da}$. Proteolytic enzyme and maximum number of missed cleavages were set to trypsin and 2, respectively. Protein candidates assigned on the basis of at least 2 sequenced peptides and an individual Mascot Score $\geq 30$ were considered as confidently identified. For quantification, ratios of TMT reporter ion intensities in the MS/MS spectra from raw datasets were used to calculate fold changes between samples. Results were filtered to $1 \%$ false discovery rate. Proteomic data have been deposited to the ProteomeXchange consortium (Vizcaíno et al., 2016) with the PRIDE partner repository with the dataset identifier PXD016951.

\section{Bioinformatics for Protein Functional Analysis}

Identified proteins were subjected to BLAST sequence homology search using command line NCBI applications against the Arabidopsis thaliana protein sequence database TAIR 10 from The Arabidopsis Information Resource repository ${ }^{2}$. Functional categorization of differentially represented proteins (DRPs) was obtained using Mercator pipeline ${ }^{3}$ for automated sequence annotation. Final outputs were integrated with data from available literature. Hierarchical clustering analysis of $\log _{2}$ transformed abundance ratios of DRPs from Trichodermatreated strawberry plants was performed using Genesis 1.8.1 platform (Sturn et al., 2002). Person's correlation as distance and average linkage clustering were chosen as parameters. Protein interaction networks were obtained with STRING v. $11^{4}$ using the A. thaliana database. Venn diagrams were depicted using a web tool at http://bioinformatics.psb.ugent.be/webtools/Venn.

\section{Statistical Analysis}

Biometric data (TY, NF, RL, RFW, and RDW), and total antioxidant capacity, ascorbic acid, total phenolic compounds, total anthocyanins and single anthocyanin content of samples were examined by one-way ANOVA using SPSS software (v.15.0 IBM, Armonk, NY, United States). Significant differences among treatments were separated using SNK (Student-Newman-Keuls) and Fisher's Least Significant Difference (LSD) post hoc tests, at the 0.05 level of significance.

\footnotetext{
${ }^{2}$ www.arabidopsis.org

${ }^{3}$ http://mapman.gabipd.org/web/guest/app/mercator

${ }^{4}$ http://string-db.org
} 


\section{RESULTS}

\section{Strawberry Growth and Yield of Strawberry Plants}

Treatments with Trichoderma harzianum strains T22 and TH1, and T. virens strain GV41 significantly enhanced total yield (TY) $(P<0.05)$ of strawberry plants, as compared to control (CTR) (Table 1). In particular, the strains T22, TH1, and GV41 increased TY by 35, 38, and 29\%, respectively. Applications of T. harzianum strains T22 and TH1 were also found to significantly increase $(P<0.05)$ the number of fruits per plant (NF) by 17 and 39\%, respectively, while a lower effect $(6 \%)$ was observed in the case of T. virens strain GV41.

All Trichoderma treatments slightly enhanced root length (RL), root fresh weight (RFW) and root dry weight (RDW), and GV41 showed the highest increase of RL (11\%), RFW (17\%) and RDW (21\%) compared to CTR, as outlined in Table 1.

In addition, no incidence of disease was observed on the plants or fruits subjected to the Trichoderma biological treatments monitored for the duration of the experiment (data not shown).

\section{Antioxidant Properties of Strawberry Fruits}

Treatments with Trichoderma strains variably affected the antioxidant capacity of fruits, as well as the corresponding total polyphenol, ascorbic acid and total anthocyanin content. In particular, application of the strain GV41 exhibited a slight increase $(8 \%)$ of antioxidant activity in strawberry samples respect to $\mathrm{CTR}(P<0.05)$, together with a significant accumulation of ascorbic acid (23\%) and total anthocyanins (31\%) $(P<0.05)$ (Table 2). Conversely, strain TH1 only promoted a significant increase $(66 \%)$ of total anthocyanin levels $(P<0.05)$.

\section{Quali-Quantitative Characterization of Individual Anthocyanins in Strawberry Fruits}

To better evaluate anthocyanin content in strawberry fruits from Trichoderma-treated plants, a dedicated quali-quantitative characterization of individual compounds was undertaken. To this purpose, mass spectrometry (MS) transitions were tentatively identified and assigned according to previous studies (Chandra et al., 2001; Määttä-Riihinen et al., 2004; Holzwarth et al., 2012); the results are reported in Supplementary Table S1, while Supplementary Figure S1 depicts a representative anthocyanin profile of a fruit sample recorded at $520 \mathrm{~nm}$. Peaks 1 and 6 were assigned to cyanidin 3-O-glucoside (cya 3-O-glc) and cyanidin derivative (cya der), respectively; both compounds exhibited an $\left[\mathrm{M}^{+}\right]$signal at $m / z$ 449, releasing cyanidin as fragment at $m / z 287$ in MS/MS experiments. As expected based on chromatographic gradient and cationic selectivity of the column, cya 3-O-glc eluted earlier than cya der. Peaks 2, 3, 4, and 5 were tentatively assigned to pelargonidin glycosides since each component showed the flavylium ion signal at $m / z 271$ (pelargonidin flavylium ion) in MS/MS experiments. In agreement with previous investigations (Holzwarth et al., 2012), the predominant

TABLE 1 | Effects of different Trichoderma strains (T22, TH1, and GV41) on the growth and productivity of strawberry plants under greenhouse conditions.

\begin{tabular}{|c|c|c|c|c|c|}
\hline \multirow[t]{2}{*}{ Treatment } & $\begin{array}{c}\text { Total Yield (TY) } \\
\text { (g/plant) }\end{array}$ & $\begin{array}{c}\text { Number of } \\
\text { fruits/plant (NF) }\end{array}$ & $\begin{array}{l}\text { Root length (RL) } \\
\text { (cm/plant) }\end{array}$ & $\begin{array}{l}\text { Root fresh weight } \\
\text { (RFW) (g/plant) }\end{array}$ & $\begin{array}{l}\text { Root dry weight } \\
\text { (RDW) (g/plant) }\end{array}$ \\
\hline & Mean \pm SD (\%) & Mean \pm SD (\%) & Mean \pm SD (\%) & Mean \pm SD (\%) & Mean \pm SD (\%) \\
\hline CTR & $125.4 \pm 21.8 \mathrm{a}$ & $6.4 \pm 1.2 \mathrm{ab}$ & $22.0 \pm 1.9 \mathrm{a}$ & $62.9 \pm 5.4 \mathrm{ab}$ & $13.5 \pm 1.1 \mathrm{bc}$ \\
\hline T22 & $168.9 \pm 25.2$ b (35) & $7.5 \pm 1.2$ c (17) & $24.5 \pm 2.2 b(11)$ & $69.3 \pm 7.8$ bcd (10) & $15.1 \pm 1.3 \mathrm{~cd}(12)$ \\
\hline $\mathrm{TH} 1$ & $173.1 \pm 24.2$ b (38) & $8.9 \pm 1.2 \mathrm{~d}(39)$ & $24.0 \pm 3.2 \mathrm{ab}(9)$ & $64.8 \pm 7.7$ abc (3) & $15.1 \pm 1.8 \mathrm{~cd}(12)$ \\
\hline GV41 & $161.6 \pm 24.1$ b (29) & $6.8 \pm 1.2 \mathrm{bc}(6)$ & $24.5 \pm 2.7 b(11)$ & $73.7 \pm 5.4 \mathrm{~d}(17)$ & $16.4 \pm 1.5 \mathrm{a}(21)$ \\
\hline
\end{tabular}

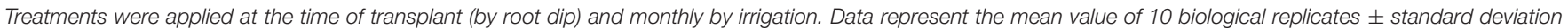

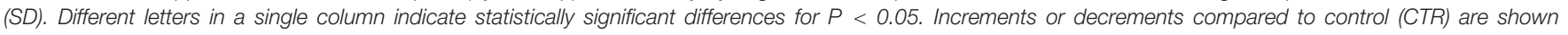
in percent (\%) and are reported in parenthesis.

TABLE 2 | Effects of the application of different Trichoderma strains (T22, TH1, and GV41) on the antioxidant properties of strawberry fruits.

\begin{tabular}{|c|c|c|c|c|}
\hline \multirow[t]{2}{*}{ Treatment } & Antioxidant capacity $[\mu \mathrm{mol}$ eq Trolox/g] & Total polyphenols [mg/g] & Ascorbic acid [mg/100g] & Total anthocyanins $[\mu \mathrm{g} / \mathrm{g}]$ \\
\hline & Mean \pm SD (\%) & Mean \pm SD (\%) & Mean \pm SD (\%) & Mean \pm SD (\%) \\
\hline CTR & $54.0 \pm 10.7 \mathrm{bc}$ & $10.9 \pm 0.1 \mathrm{a}$ & $116.8 \pm 12.6 \mathrm{bc}$ & $809.0 \pm 13.0 \mathrm{bc}$ \\
\hline T22 & $47.9 \pm 0.9 \mathrm{abc}(-11)$ & $8.6 \pm 2.9 \mathrm{a}(-21)$ & $107.0 \pm 13.1 \mathrm{~b}(-8)$ & $818.1 \pm 23.5 \mathrm{bc}(1)$ \\
\hline $\mathrm{TH} 1$ & $42.8 \pm 16.7 \mathrm{a}(-21)$ & $9.5 \pm 8.4 \mathrm{a}(-13)$ & $102.8 \pm 30.8 \mathrm{ab}(-12)$ & $1340.7 \pm 15.6$ a (66) \\
\hline GV41 & $58.3 \pm 0.3$ c (8) & $10.4 \pm 2.5 \mathrm{a}(-5)$ & $144.2 \pm 2.5 d(23)$ & $1056.6 \pm 1.9 \mathrm{~b}(31)$ \\
\hline
\end{tabular}

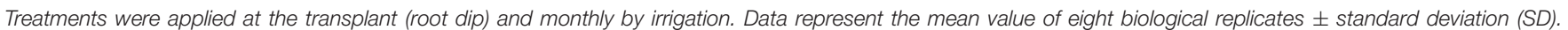

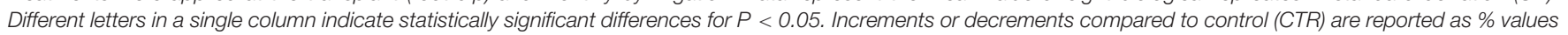
in parenthesis. 
anthocyanin (peak 2) was pelargonidin 3-O-glucoside (pel 3$O$-glc) with a $\left[\mathrm{M}^{+}\right]$signal at $m / z$ 433. On the other hand, peak 3, 4 and 5 were assigned to pelargonidin 3-O-rutinoside (pel 3-O-rut), pelargonidin 3-O-malonyl-glucoside (pel 3-Omal-glc) and pelargonidin 3-O-acetyl-glucoside (pel 3-O-ac-glc) based on corresponding $\left[\mathrm{M}^{+}\right]$signals at $m / z 579,519$ and 475 , respectively.

Based on above-mentioned results, LC-DAD-assisted quantitative measurements of individual anthocyanins in fruits from plants exposed to the Trichoderma spore suspensions (Figure 1) confirmed the increment of total compounds already detected by colorimetric test (Table 2). The highest increases were observed with the application of strain TH1, which promoted the accumulation of cya 3-O-glc (82\%), pel 3-O-glc (70\%), pel 3-O-rut (77\%), pel 3-O-ac-glc (24\%) and cya der $(72 \%)(P<0.05)$, compared to CTR; no significant differences were envisaged for pel 3-O-mal-glc. Similarly, the strain GV41 increased the accumulation of all the individual anthocyanins $(P<0.05)$, with the exception of cya der. Finally, the application of strain T22 only determined a $24 \%$ increase in pel 3-O-ac-glc content $(P<0.05)$.

\section{Proteomic Analysis of Strawberry Fruits}

With the aim of evaluating molecular effectors/metabolic pathways that underlie the above-mentioned effects of Trichoderma spp. on strawberry fruits, and obtaining original information on fruits from a plant treated with BCAs, protein extracts from berry samples of plants inoculated with Trichoderma strains T22, TH1, and GV41 were comparatively evaluated to the control by a TMT-based proteomic approach. This quantitative analysis allowed the identification of 3294 proteins and measuring the relative quantitative levels of 3014 plant proteins (data available in PRIDE repository with dataset identifier PXD016951) that found a counterpart in 3262 and 2982 redundant Arabidopsis thaliana entries in TAIR 10 database, respectively, plus additional 32 plant sequence entries not having a homolog in the same sequence data inventory. This proteomic analysis of the strawberry did not note the presence of Trichoderma proteins in the fruit extracts. Above-mentioned proteins were further filtered for abundance fold changes $\geq 1.50$ or $\leq 0.66$ (T22, TH1, and GV41 vs. CTR) $(P \leq 0.05)$ and accession redundancy, thus ascertaining 333 differentially represented proteins (DRPs) associated with various Trichoderma treatments (Supplementary Table S2). The latter corresponded to 323 non-redundant $A$. thaliana sequence entries in TAIR 10 database plus additional 10 plant sequence entries not having an $A$. thaliana counterpart. In particular, 75, 45, and 253 DRPs were observed for Trichoderma strains $\mathrm{T} 22, \mathrm{TH} 1$, and GV41, respectively. A Venn diagram representation of these DRPs showed a number of unique and shared components between different Trichoderma treatments (Figure 2). Hierarchical clustering of abundance ratios and distribution of DRPs between different Trichoderma strains highlighted that most significant quantitative changes occurred after treatment with $T$. virens GV41, followed by that with T. harzianum T22 and TH1 (data not shown and Figure 2). Resultant DRPs were functionally indexed through an initial assignment obtained with Mercator software, followed by a functional group cataloguing including information from the Bevan classification (Bevan et al., 1998) and recent literature data (Figure 3 and Supplementary Table S3). This analysis attributed a function to all proteins, except 23 molecular species that were not assigned to any known ontology or functional group. Thus, DRPs were mostly related to the functional category of protein metabolism (including components involved in protein biosynthesis, protein degradation and protein translocation) (20\%), stress response (including components associated with redox homeostasis, external stimuli response and protein modification) (17\%), carbon and energy metabolism (including enzymes related to carbohydrate metabolism, energy and photosynthesis) (14\%), vesicle trafficking (9\%), and secondary metabolism (including enzymes catalyzing biosynthesis/degradation of secondary metabolites and phytohormones) (7\%), thus highlighting prominent molecular mechanisms and metabolic pathways modified following Trichoderma treatments. No major differences in the functional distribution were observed when DPRs from plants treated with strains T22, TH1, and GV41 were considered singularly (data not shown). Functional enrichments of above-mentioned proteins for biological processes, and molecular functions and KEGG pathways confirmed the involvement of most DRPs in the response to different chemical stimuli, in binding to ions/small molecules and catalytic activity, or in the biosynthesis of secondary metabolites, oxidative phosphorylation, and carbon and protein metabolism, respectively (Supplementary Table S4). Heat-map pictures originated from hierarchical clustering of quantity ratios of DRPs for each functional group were reported in Figure 4 and Supplementary Figures S2-S9. These figures describe the relative quantitative representation profile of the different strawberry proteins as result of the different Trichoderma treatments, as related to CTR. A general coherent qualitative trend of DRPs between the various treatments with Trichoderma strains was observed, with a very limited number of exceptions. In the subsequent sections focused on the most represented protein functional groups, these heat-map pictures are discoursed together with corresponding DRPs and metabolic pathways/molecular processes.

Bioinformatic analysis of DRPs with STRING allowed predicting a strawberry functional protein association map based on A. thaliana homolog counterparts, which at high confidence (0.7) revealed a predominant highly ramified network linking together 182 components, plus twelve binary/ternary molecular complexes (Figure 5 and Supplementary Table S5). The involvement of most DRPs (54.6\% of total number) in this major network emphasized the occurrence of a functional assembly bridging different deregulated metabolic pathways and molecular processes, which underlies the physiological adaptation of strawberry fruits to the occurrence of Trichoderma strains in plant roots. As mentioned above, most of the knots present in this network were associated with DRPs from treatment with $T$. virens GV41. When a medium confidence (0.4) was used, a unique highly ramified network linking together 287 DRPs $(86.2 \%$ of their total number) was observed (data not shown). Overall, above-mentioned proteomic results suggested that various 

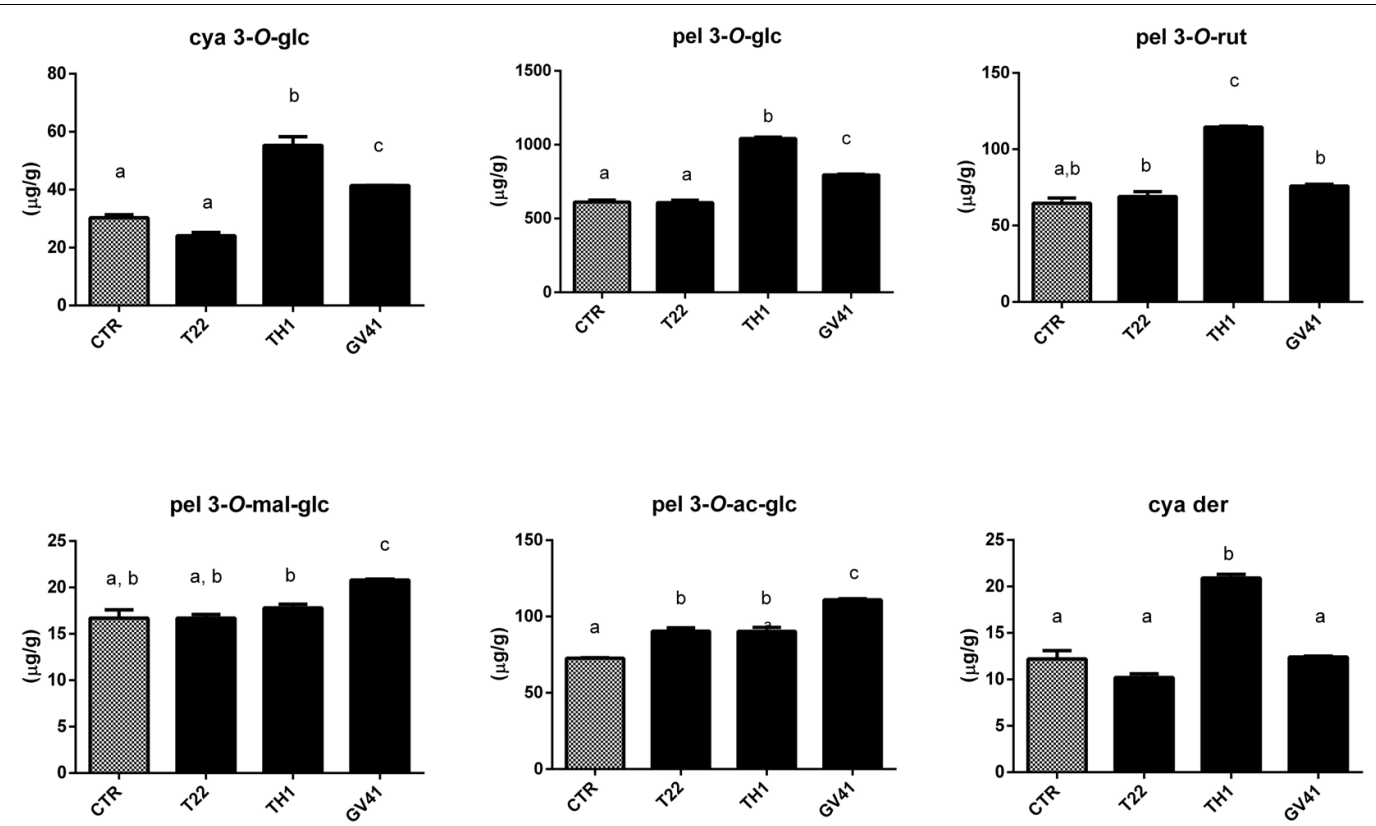

FIGURE 1 | Concentration of individual anthocyanins in strawberry fruits produced by plants subjected to the treatment with Trichoderma strains (T22, TH1, and GV41), as compared to control (CTR). Results on cyanidin 3-O-glucoside (cya 3-O-glc), pelargonidin 3-O-glucoside (pel 3-O-glc), pelargonidin 3-O-rutinoside (pel 3-O-rut), pelargonidin 3-O-malonyl-glucoside (pel 3-O-mal-glc), pelargonidin 3-O-acetyl-glucoside (pel 3-O-ac-glc) and cyanidin derivative (cya der) are shown. Data were reported as $\mu \mathrm{g} / \mathrm{g}$ sample, and represent the mean value of 8 biological replicates \pm standard deviation (SD). Different letters on the bars indicate statistically significant differences $(P<0.05)$.

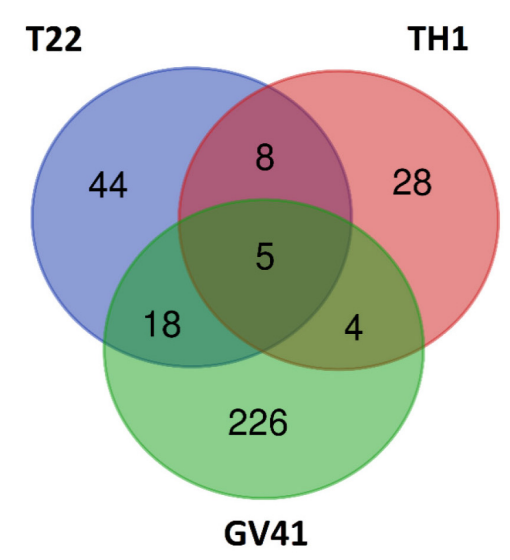

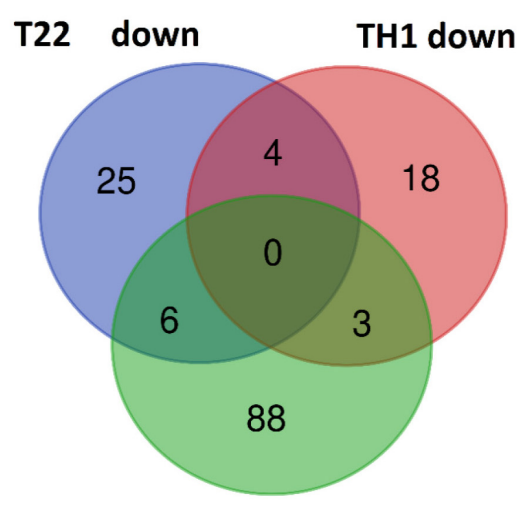

GV41 down

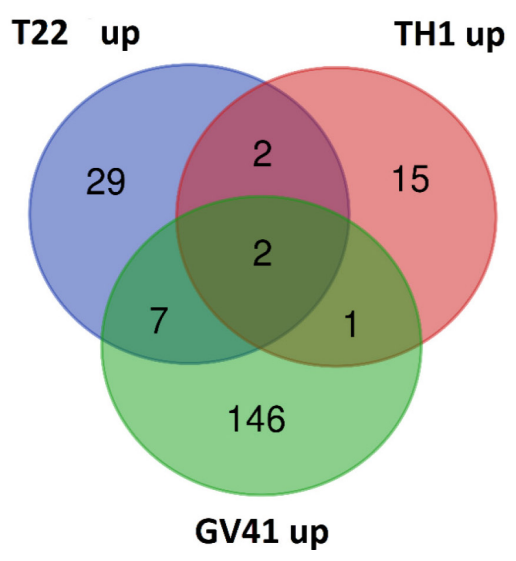

FIGURE 2 | Venn diagram showing differentially represented proteins present in strawberry fruits produced by plants subjected to the treatment with Trichoderma strains (T22, TH1, and GV41), as compared to control. Diagrams refer to all differentially represented proteins (left), those down-represented (middle) and over-represented (right), respectively.

metabolic, energetic and signaling processes, together with a number of plant external stimuli-/stress-responsive mechanisms, are simultaneously regulated in strawberry fruits as result of the plant treatment with different Trichoderma strains.

\section{DISCUSSION}

Fungi belonging to the genus Trichoderma are used as successful plant growth enhancers, biostimulants, biofertilizers, and as effective biocontrol agents against various pathogens (Woo et al., 2014; Lorito and Woo, 2015). Some of these positive effects have been related to the microbial release of bioactive metabolites and elicitor proteins in the plant rhizosphere (Harman et al., 2004a,b; Vinale et al., 2014). Proteomic and transcriptomic studies on plant root, leaf tissues, and seedlings suggested that this growth-promoting activity of Trichoderma spp. is associated with different molecular events in the host, such as: (i) an increased nutrient uptake (Altomare et al., 1999); (ii) variations in phytohormone levels and corresponding 


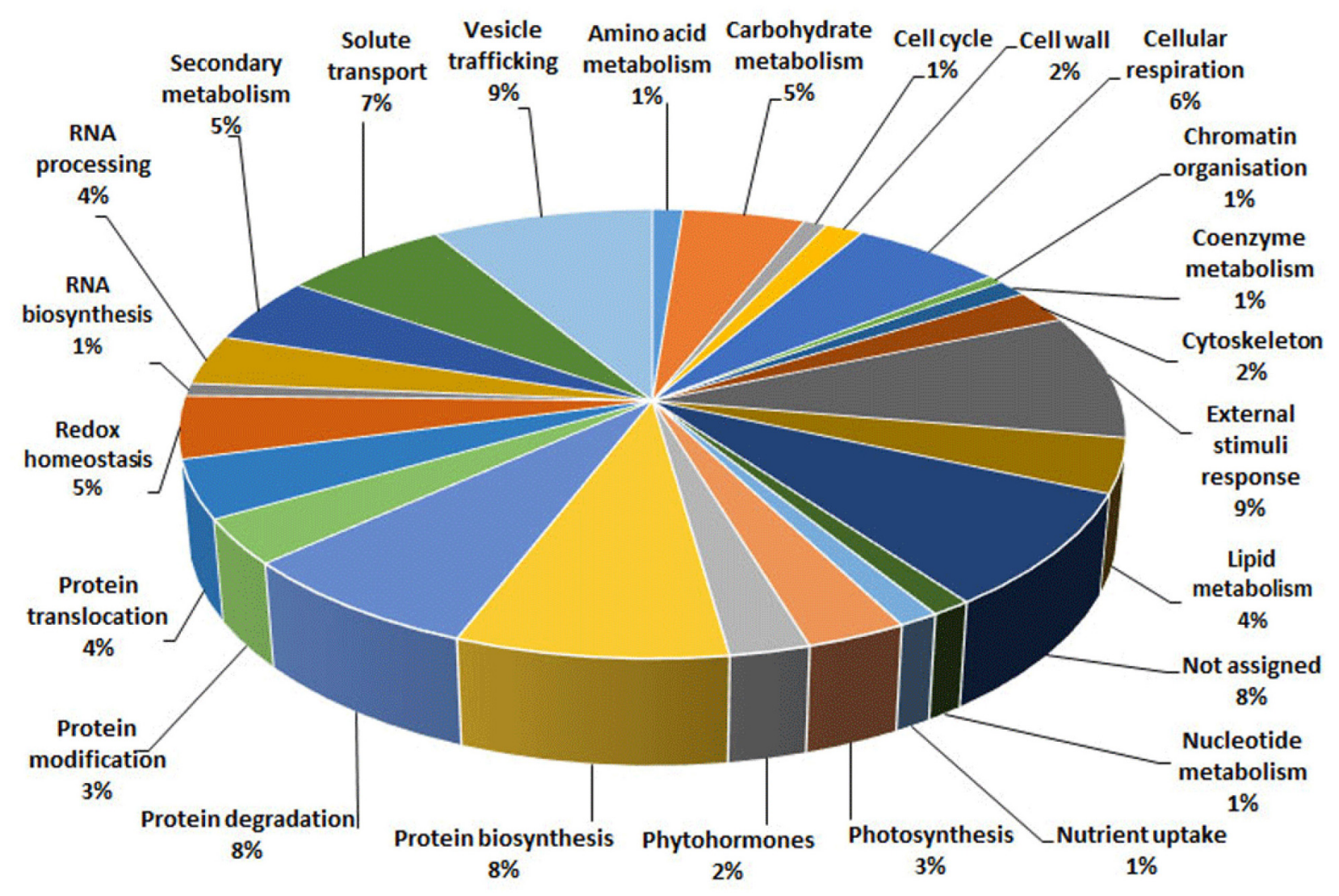

FIGURE 3 | Functional distribution of differentially represented proteins present in strawberry fruits produced by plants subjected to the treatment with Trichoderma strains (T22, TH1, and GV41), as compared to control (CTR). Identified protein species were initially assigned with Mercator software (Supplementary Table S3), followed by a functional group cataloguing including information from the Bevan classification (Bevan et al., 1998) and recent literature data.

induced metabolic processes (Harman et al., 2004a; Caporale et al., 2014); (iii) a general augmented carbon and energy metabolism (Shoresh et al., 2010); (iv) a higher photosynthetic efficiency (Shoresh et al., 2010). Molecular data on fruit tissues are scant in the literature and mainly limited to specific genes/proteins/metabolites (Singh et al., 2018).

\section{Growth Promotion and Related Molecular Mechanisms}

This study on strawberry plants and fruits confirmed the ability of the selected $T$. harzianum (T22 and TH1) and T. virens (GV41) strains to act as growth-promoting agents. In fact, these treatments increased significantly strawberry plant total yield (from a value of $29 \%$ for GV41 to $38 \%$ for TH1), augmented the number of corresponding fruits (from a value of $6 \%$ for GV41 to 39\% for TH1) and promoted corresponding root growth (from a value of $12 \%$ for TH1 and T22 to $38 \%$ for GV41), when compared to control.

It has already been reported that the yield in strawberry plants is strongly dependent on micronutrient availability in the soil (Valentinuzzi et al., 2015). Our proteomic results on strawberry fruits confirmed the positive effect of Trichoderma strains in facilitating plant nutrient uptake, as demonstrated by the observed over-representation of membrane proteins devoted to (neutral and ionic) solute transport (Supplementary Table S4) and, in general, by the functional enrichment of biological processes related to the response to various chemicals (Supplementary Table S4). This phenomenon was more evident for GV41, but also detectable in T22 and TH1. Among the abovementioned augmented proteins, worth mentioning are plasma membrane intrinsic proteins $1 ; 4,2,2 \mathrm{~A}$ and $2 ; 5$ allowing the cellular import of water and small neutral molecules (Wang et al., 2016), as well as membrane transporters for ATP/ADP, malate, nucleotide derivatives, and xanthine/uracil/ascorbate (Supplementary Figure S2). The selective over-representation of the latter protein in Trichoderma GV41-treated plants may be related to the augmented levels of ascorbic acid measured in the corresponding fruit (Table 2). In the abovementioned context, it could also be considered the observed over-representation of five $\mathrm{H}^{+}$-translocating and two $\mathrm{Ca}^{2+}$ translocating ATPases, which couple the well-known ion fluxes associated with plant response to BCAs (Shoresh et al., 2010) to energy production (Supplementary Figure S2). Additional overrepresented membrane components devoted to phytohormone, oxidant and proton translocation were ABCG transporters (3 pleiotropic drug resistance proteins) (see below) and two 


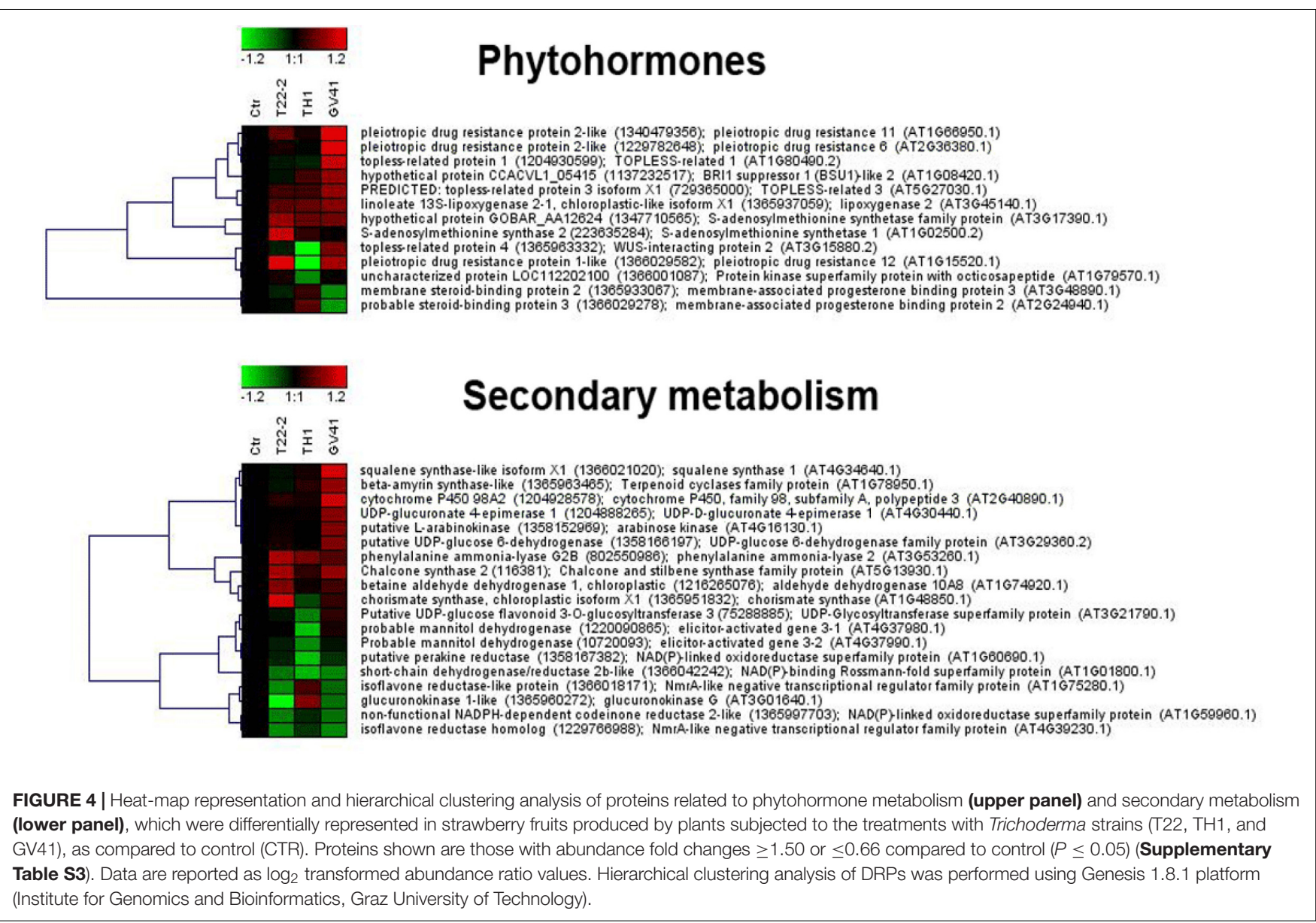

$\mathrm{H}^{+}$-exporting pyrophosphatases. The latter proteins have been widely recognized to play an essential role in auxin-mediated leaf/fruit development, biomass accumulation and crop yield increase ( $\mathrm{Li}$ et al., 2005; Schilling et al., 2014; Yang et al., 2014). On the other hand, the observed down-representation of the nutrient-related chloroplast nitrogen regulatory protein PII $(\mathrm{G} \ln \mathrm{B})$ in fruits from treated plants was in line with previous observations on the reduced transcription of the corresponding gene in the presence of elevated levels of $\mathrm{N}$-containing metabolites (Hsieh et al., 1998; Supplementary Figure S2). GlnB also played an essential role in regulating target proteins in response to cellular ADP/ATP levels and 2-oxoglutarate status, thereby coordinating the plant carbon/nitrogen balance and regulating specific metabolic pathways (Uhrig et al., 2009). In the whole, our gel-free proteomic approach revealed abundance changes of membrane nutrient transporter proteins already ascertained by transcriptomic studies (De Palma et al., 2016, 2019), but whose solubility hampered corresponding detection in previous gel-based methods.

In addition to above-mentioned $\mathrm{H}^{+}$- and $\mathrm{Ca}^{2+}$-translocating ATPase machineries, proteomic analysis of strawberry fruits also provided information on additional mechanisms ensuring the greater energy supply requested in Trichoderma-treated plants to sustain the observed plant growth and development.
Thus, different proteins involved in carbohydrate (starch, sucrose and nucleotide-sugar) metabolism ( $\beta$-galactosidase, $\beta$-fructofuranosidase, granule-bound starch synthase 1 , sucrose synthase 1F, 4 and 6, xyloglucan 6-xylosyltransferase, UDPglucuronate 4-epimerase 1, glucuronokinase 1, UDP-glucose 6dehydrogenase, sorbitol dehydrogenase and arabinose kinase), glycolysis and tricarboxylic acid cycle (two phosphofructokinase isoforms, pyruvate kinase, isocitrate dehydrogenase, ATP lyase and 2-oxoglutarate dehydrogenase), and alcoholic fermentation (two pyruvate decarboxylase isoforms) showed augmented levels in fruit after Trichoderma treatments (Supplementary Figure S3). This effect was again more evident in Trichoderma GV41-treated plants, confirming the already-mentioned straindependent potential of BCAs (Tucci et al., 2011; Fiorentino et al., 2018; Marra et al., 2019). These results were in good agreement with previous proteomic observations on root and leaf tissues from maize, tomato, cucumber and grapevine plants (Segarra et al., 2007; Shoresh and Harman, 2008; Shoresh et al., 2010; Palmieri et al., 2012; Manganiello et al., 2018). Conversely, all mitochondrial components of the mitochondrial ATP synthase and cytochrome $\mathrm{C}$ reductase complexes showed reduced levels after microbial treatments (Supplementary Figure S3), while a mixed behavior was observed for proteins involved in photosynthesis. The first phenomenon may be related to a 


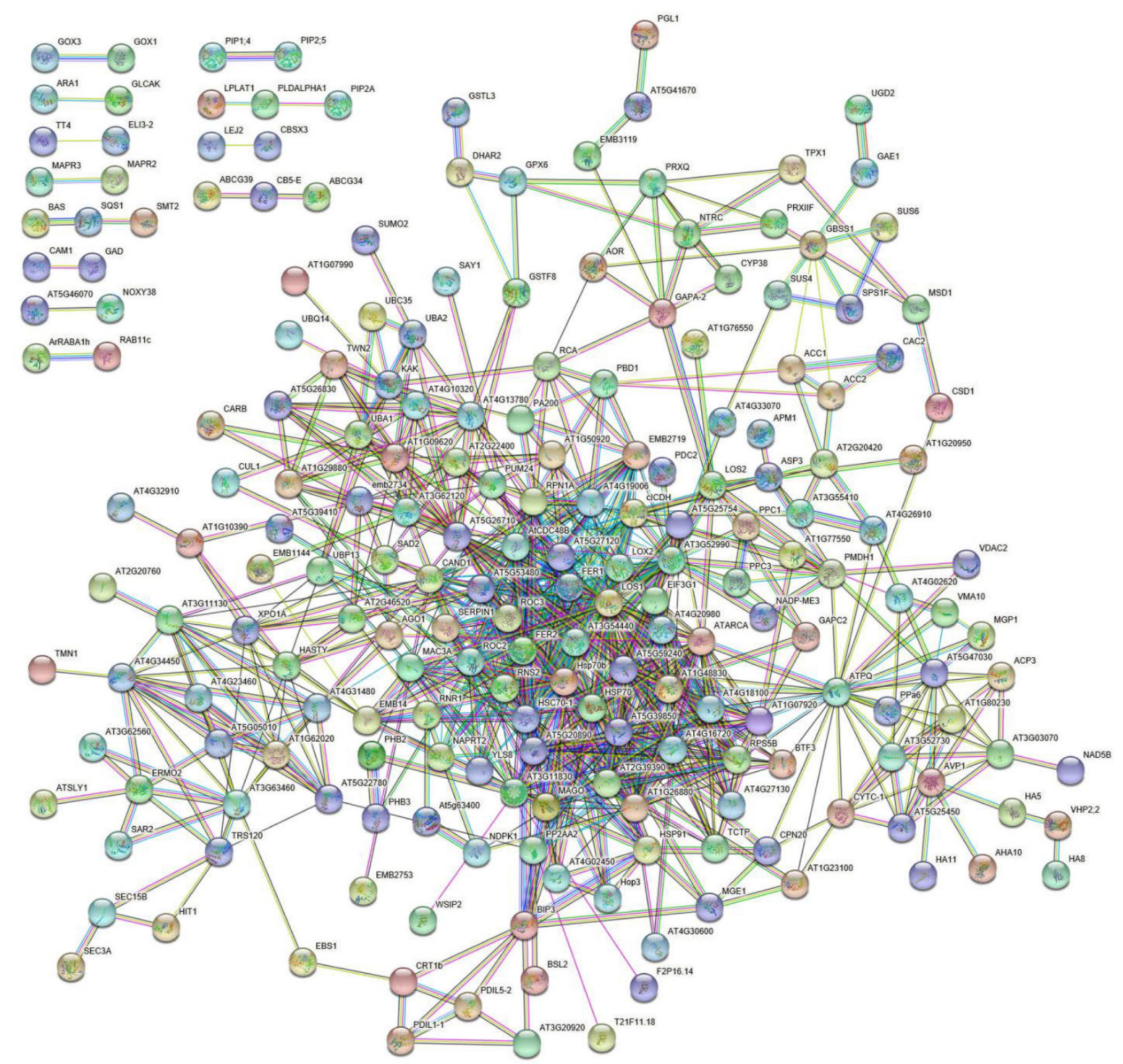

FIGURE 5 | STRING analysis of differentially represented proteins present in strawberry fruits produced by plants subjected to the treatments with Trichoderma strains (T22, TH1, and GV41), as compared to control (CTR). Functional protein associations were based on data recorded for A. thaliana protein homologs. Only high-confidence interactions (0.7) are shown. Protein codes are reported in Supplementary Table S5.

cell attempt to limit generation of reactive oxygen species (ROS) side products during oxidative phosphorylation, in a physiological plant condition where plant cells are already exposed to significant oxidant fluxes (see below) (Shoresh et al., 2010). On the other hand, components of the NADH dehydrogenase complex (complex I), which is believed to belong to the minimal assembly required for the transfer of electrons from NADH to the respiratory chain, showed augmented levels after Trichoderma treatments.

Observed plant growth and development in Trichodermatreated plants also corresponded to increased fruit representation levels of a number of components present in protein biosynthetic machineries involved in: (i) RNA biosynthesis and processing ( 2 and 8 in number, respectively); (ii) production of amino
acid-tRNAs (8 in number); (iii) assembling of large/small ribosomal subunits ( 8 in number); (iv) polypeptide chain translation initiation/elongation activities (translation initiation factor 3 subunits $G$ and L, and elongation factor G); (v) protein translocation from cytoplasm to cell nucleus and endoplasmic reticulum (3 and 7 in number, respectively) (Supplementary Figures S6, S7). Sporadic proteins showing an opposite quantitative trend were also observed. Abovementioned components seemed essential to fuel novel enzymes and structural proteins to developing fruit cells and growing tissues (Shoresh and Harman, 2008), as revealed by the number of over-represented species mentioned in the previous paragraphs and the augmented levels of constitutive elements present in evolving cell wall (5 in number) and cytoskeleton (5 in number) 
compartments (Supplementary Figure S8). In the latter group can also be included the cell division protein FtsZ that, together with all other strawberry deregulated components present in the cell cycle catalog, also showed augmented levels after Trichoderma treatment. This protein is a structural homolog of tubulin and mediates ring formation at the chloroplast division site, and thus is essential for plant growth (Vitha et al., 2001). A request for augmented protein levels in treated plants has also to be considered in light of the need of additional defensive components (see below).

\section{Secondary Metabolites and Related Biosynthetic Pathways}

This study also showed that Trichoderma spp. treatment of plants favored accumulation of anthocyanins and other antioxidants in strawberry fruits, with a pattern that was straindependent. In particular, application of two microorganisms increased significantly total content of anthocyanins (31 and $66 \%$ for GV41 and TH1, respectively), ascorbic acid (23\% for GV41) and corresponding antioxidant capacity (8\% for GV41). Chromatographic measurements of individual anthocyanins confirmed the above-mentioned total increment, highlighting the accumulation of all measured compounds except pel 3-O-mal-glc and pel 3-O-ac-glc in TH1 and GV41, respectively. Induction of antioxidant metabolites in plant tissues of BCA-treated plants has already been reported; for example, T. harzianum inoculation was described to increase polyphenolic content and antioxidant activity in grape (Pascale et al., 2017), as well as GSH/GSSG and ASA/DHA ratios in tomato seedlings (Mastouri et al., 2012). Similarly, T. asperellum root colonization of cucumber plants augmented total antimicrobial polyphenols (Yedidia et al., 2003). Our proteomic measurement of enzymes involved in biosynthesis of secondary metabolites provided a rationale to the above-mentioned increase of anthocyanins in strawberry fruits. Indeed, it demonstrated augmented levels of phenylalanineammonia lyase (PAL) and chorismate synthase, which control the first reaction steps of the phenylpropanoid pathway yielding phenolic compounds (including anthocyanins), and other enzymes (chalcone and stilbene synthase, UDP-glucuronate 4-epimerase, glucokinase, UDP-glucose 6-dehydrogenase, arabinose kinase) assisting the conversion of corresponding intermediates into final compounds, or forming UDP-sugar moieties to be included into corresponding structures (Figure 4). To increase anabolic efficiency toward anthocyanin production, proteins (elicitor-activated gene 3-1 and 3-2, and two isoflavone reductases) catalyzing transformation of above-mentioned secondary metabolites into lignin derivatives were also downrepresented. These results well resembled the augmented PAL levels already reported in roots and leaves of other Trichodermatreated plants (Shoresh and Harman, 2008; Shoresh et al., 2010; De Palma et al., 2016).

Additional deregulated secondary metabolism enzymes showing augmented levels after Trichoderma application were squalene synthase and $\beta$-amyrin synthase, which are involved in the biosynthesis of sesquiterpenoids/triterpenoids (Figure 4). Terpenoids represent important constituents of herbivore-induced plant volatiles that deter herbivores and/or attract their predators (Sharma et al., 2017). They serve as airborne signals that can induce defense responses in systemic undamaged parts of the plant, and prime defense responses in neighboring plants. Our determinations were in good agreement with those on corresponding metabolic pathways and metabolites in tomato plants challenged with T. harzianum (Manganiello et al., 2018), confirming that fungal treatment can influence the plant defensive volatilome.

\section{Antioxidant Enzymes and Related Molecular Processes}

Augmented production of antioxidant metabolites in strawberry fruits may occur as consequence of the induction of different defense mechanisms (Contreras-Cornejo et al., 2011), which follow plant interactions with specific BCAs or pathogens. For example, expression of $\mathrm{Pal}$ genes is induced by jasmonic acid (JA)/ethylene (ET) signaling during plant defense response (Shoresh et al., 2010), and augmented levels of anthocyanins have already been reported to attenuate the effects of ROS produced to generate an hostile environment in plant tissues after microorganism challenge (Figueroa-Balderas et al., 2006; Senthil-Kumar and Mysore, 2010; Mathys et al., 2012). In particular, it has already been demonstrated that plant cocultivation with T. asperellum increased anthocyanin production in A. thaliana leaves (Contreras-Cornejo et al., 2011). Our proteomic experiments showed that this augmented production of antioxidants in fruits from treated plants corresponded to a widespread down-representation of enzymes limiting the detrimental effects of ROS (15 in number and corresponding to different redox protective machineries) (Supplementary Figure S4). These findings apparently contrast with previous observations on root and leaf tissues of Trichoderma-challenged plants, which report an over-representation of antioxidant and toxicant-scavenging enzymes therein [Segarra et al., 2007; Shoresh and Harman, 2008; Shoresh et al., 2010; Mastouri et al., 2012; De Palma et al., 2016, 2019; Perazzolli et al., 2016; Zhang et al., 2017; Manganiello et al., 2018), although in some cases a coherent quantitative trend was also described (Vitti et al., 2015; Rubio et al., 2017). Thus, our results on this antioxidant metabolite-rich fruit suggested that either the increased concentration of these small protective compounds after fungal challenge was enough to remodulate ROS levels, without the need of augmented antioxidant protein machineries that are repressed to save plant energy, or the biosynthesis of the latter components was selectively down-regulated to allow high basal levels of detrimental oxidants to contrast bacterial challenge. Future investigations are required in this context.

\section{Defense Processes and Related Molecular Mechanisms}

Proteomic analysis of Trichoderma-treated plants also highlighted defensive signaling pathways and corresponding down-stream mechanisms modulated following fungusplant interaction; a number of them have already been reported to prevent pathogen colonization (Shoresh et al., 2010; 
Pérez and Goossens, 2013; Guerreiro et al., 2016; Yuan et al., 2017; Aldon et al., 2018; Yu et al., 2018). In particular, signaling pathways involving $\mathrm{Ca}^{2+}$, JA, ET and brassinosteroid (BR) effectors appear to be modulated in strawberry fruits following the interaction with Trichoderma. This was suggested from the observed modified levels of: (i) a number of $\mathrm{Ca}^{2+}$-binding sensors and a MAP3K (10 in number, all showing downrepresentation except coherent $\mathrm{Ca}^{2+}$-translocating ATPase concentrations ensuring ion expulsion from the cell); (ii) lipoxygenase 2 involved in JA biosynthesis (showing overrepresentation); (iii) S-adenosylmethionine synthase 1 and 2 involved in ET biosynthesis (showing over-representation); (iv) BR-related membrane-associated progesterone-binding proteins 2 and 3, and BRI suppressor 1 and 2 (showing a mixed but coherent quantitative trend); and (v) topless-related protein 1, 2 and 3 (Figure 4 and Supplementary Figures S2, S7). Some proteins mentioned above (especially those sensitive to $\mathrm{Ca}^{2+}$ ) are involved in signal decoding and transduction mechanisms leading to a rapid down-stream activation of cellular ROS burst, protein phosphorylation and transcriptional reprogramming events, as well as to the biosynthesis of defenserelated phytohormones JA, ET, and salicylic acid (SA). A number of these quantitative protein changes were in agreement with those already determined in other proteomic/transcriptomic studies on root/leaf tissues from Trichoderma-treated maize, tomato and cucumber plants (Segarra et al., 2007; Shoresh et al., 2010; Manganiello et al., 2018; Nogueira-Lopez et al., 2018; De Palma et al., 2019). Notwithstanding this investigation strongly suggested the activation of JA- and ET-mediated defense processes also in fruits from Trichoderma-treated strawberry plants, a real comprehension of those involving $\mathrm{Ca}^{2+}$ and $\mathrm{BR}$ action will deserve future dedicated studies (on other plant tissues and according to a time-basis). In fact, $\mathrm{Ca}^{2+}, \mathrm{BR}$, and $\mathrm{ET}$ concentration changes are also known to modulate plant growth and to proceed with different rates (Hepler, 2005; Yu et al., 2018), and variable levels of these molecules have been reported in other tissues after fungal challenge (Navazio et al., 2007).

This study also demonstrated a clear activation (23 overrepresented proteins) of a number of protein machineries involved in cellular vesicle trafficking in fruits from treated plants (Supplementary Figure S8); these vesicles have been reported as essential structures to dump out high- and low-mass compounds involved in plant innate immunity. In fact, since antimicrobials are also toxic to plant cells themselves, they have to be safely delivered to target sites in a separate compartment (Yun and Kwon, 2017). Because immune responses generally require energy otherwise used for the other metabolic processes, it is also very important to properly control duration/strength of these secretory activities. This can be achieved by regulating the sensing of immune signals and the delivery/discharge of extracellular immune molecules, all of which are controlled by membrane trafficking in plant cells. Thus, components of the clathrin coated vesicle machinery, coat protein I and II coatomer machineries, or regulating membrane tethering and fusion were over-represented in fruits from Trichodermatreated plants, suggesting also in this case the occurrence of this physiological phenomenon (Supplementary Figure S8).
Among above-mentioned immunity-related components, worth mentioning are exocyst complexes that were already reported to transport anthocyanins between different plant cell subcellular compartments (Pecenková et al., 2017). Preliminary evidence of quantitative changes in few of the above-mentioned protein families were observed in leaves of grapevine plants challenged with T. harzianum T39 (Perazzolli et al., 2016).

Finally, a number of proteins (52 in number) known to elicit a protective action against biotic/abiotic stresses showed variable quantitative levels in fruits from fungal-treated plants, highlighting a significant remodeling of the corresponding defense effector molecular machineries (Supplementary Figures S4, S7). Significant differences were observed among either the effect of different Trichoderma strains (with most frequent changes in GV41) and components belonging to the same protein family. Regarding heat shock proteins (HSPs), chaperones and protein disulfide-isomerases (PDIs), T. virens GV41 was observed to increase the representation of different HSP70 isoforms, HSP91 and DNAJ protein, while it decreased the concentration of various chaperones and HSP20; depending on the isoform, PDIs showed variable levels (Supplementary Figure S4). No significant changes were observed in the case of T. harzianum T22 and TH1. On the other hand, a number of proteins involved in the plant response to abiotic stresses also showed quantitative variations. This is the case of some CBS domain-containing protein and late embryogenesis abundant protein isoforms, as well as temperature-induced lipocalin, stress-inducible protein, stress induced protein, universal stress protein A, stress response protein, mucin 22-like protein and metallothionein, which were generally down-represented in T. virens GV41 and overrepresented in T. harzianum T22 (Supplementary Figures S4, S7). A similar quantitative trend was also observed for proteins involved in the plant response to biotic stresses, namely cysteine and serine protease inhibitors, thaumatin domain-containing protein, MLP-like protein 28, Bet v I type allergen, Fra a 1-E allergen chain A and Fra A3 allergen chain B, which generally showed reduced levels in $T$. virens GV41 and a higher representation in T. harzianum T22 and TH1. Data on antioxidant proteins have already been described in previous paragraphs. Various defense components reported above have already been demonstrated to show quantitative variations in root and leaf tissues of bean, maize, tomato, cucumber, and grapevine plants treated with Trichoderma strains (Marra et al., 2006; Segarra et al., 2007; Shoresh and Harman, 2008; Perazzolli et al., 2016; Manganiello et al., 2018; Nogueira-Lopez et al., 2018; De Palma et al., 2019). The distinct pattern of the allergens present in strawberry fruits depending on the Trichoderma spp. used for plant treatment prompts us to suggest the development of future investigations with the aim of evaluating novel food products with specific characteristics for human consumption.

\section{CONCLUSION}

This study demonstrated that the treatment of strawberry plants with different Trichoderma can either influence the relative 
yield, growth and productivity, as well as the accumulation of anthocyanins and other antioxidants in the corresponding fruits. These findings indicated that the positive effects observed by the application of Trichoderma-based products to the developing plant are also transferred to fruits, thus modulating different physiological processes and describing the molecular mechanisms that positively influence food quality and consumer health.

In recent years, with the changing perception by governing bodies to implement precautionary measures that reduce the use of chemical phytosanitary products in agriculture, a great effort has been spent in the development of alternative methods for crop protection. In addition to the valuable influence that Trichoderma treatments have demonstrated on the plant, increased strawberry fruit production and enhanced nutritional properties, plus its known success as a biological control agent and its acceptance as a natural product for use in diverse crop production systems, confirms the important role that this beneficial microbe can play in sustainable agricultural while safeguarding the well-being of the consumer and the environment.

\section{DATA AVAILABILITY STATEMENT}

All datasets generated for this study are included in the article/Supplementary Material.

\section{AUTHOR CONTRIBUTIONS}

NL and SW planned and designed the experiments. NL performed the field research, sample collection, and biometric analysis. AMS, SC, and AS performed the proteomics analysis

\section{REFERENCES}

Aaby, K., Mazur, S., Nes, A., and Skrede, G. (2012). Phenolic compounds in strawberry (Fragaria $\mathrm{x}$ ananassa Duch.) fruits: composition in 27 cultivars and changes during ripening. Food Chem. 132, 86-97. doi: 10.1016/j.foodchem. 2011.10.037

Aaby, K., and Remberg, S. F. (2015). "Strawberry phenolics and impact of ripening," in Processing and Impact on Active Components in Food, ed. V. R. Preedy (Cambridge, MA: Academic Press).

Aldon, D., Mbengue, M., Mazars, C., and Galaud, J. P. (2018). Calcium signalling in plant biotic interactions. Int. J. Mol. Sci. 19:665. doi: 10.3390/ijms19030665

Altomare, C., Norvell, W. A., Bjorkman, T., and Harman, G. E. (1999). Solubilization of phosphates and micronutrients by the plant-growthpromoting and biocontrol fungus Trichoderma harzianum Rifai 1295-22. Appl. Environ. Microbiol. 65, 2926-2933. doi: 10.1128/aem.65.7.2926-29 33.1999

Anttonen, M. J., Hoppula, K. I., Nestby, R., Verheul, M. J., and Karjalainen, R. O. (2006). Influence of fertilization, mulch color, early forcing, fruit order, planting date, shading, growing environment, and genotype on the contents of selected phenolics in strawberry (Fragaria x ananassa Duch.) fruits. J. Agric. Food Chem. 54, 2614-2620. doi: 10.1021/acs.jafc.7b0381

Armbruster, D. A., and Pry, T. (2008). Limit of blank, limit of detection and limit of quantitation. Clin. Biochem. 29(Suppl 1), S49-S52.

Baker, R. (1988). Trichoderma spp. as plant-growth stimulants. CRC Crit. Rev. Biotechnol. 7, 97-106. and interpretation of the data. SW, AS, NL, RM, and FV assisted in the interpretation of results and in the writing of the manuscript. AT and PV defined the experimental protocols for the antioxidant capacity, total phenolic, ascorbic acid, and anthocyanins content in fruits, and performed data elaboration and analyses. All authors contributed to the article and approved the submitted version.

\section{FUNDING}

This work was supported by the following projects: MIURPON (grant number Linfa 03PE_00026_1; grant number Marea 03PE_00106), POR FESR CAMPANIA 2014/2020- O.S. 1.1 (grant number Bioagro 559); MISE CRESO (grant number Protection $n$. F/050421/01-03/X32); PSR Veneto 16.1.1 (grant number Divine n. 3589659); European Union Horizon 2020 Research and Innovation Program, ECOSTACK (grant agreement no. 773554); ProBio IZSM (Portici), n. D01 6309, 14/12/2016; CNR project NUTR-AGE (FOE-2019, DSB.AD004.271).

\section{ACKNOWLEDGMENTS}

The authors thank Dr. Luigi De Vitto for providing the strawberry plants, and Koppert Biological Systems, Rotterdam, Netherlands for fungal inocula.

\section{SUPPLEMENTARY MATERIAL}

The Supplementary Material for this article can be found online at: https://www.frontiersin.org/articles/10.3389/fmicb. 2020.01364/full\#supplementary-material

Bevan, M., Bancroft, I., Bent, E., Love, K., Goodman, H., Dean, C., et al. (1998). Analysis of $1.9 \mathrm{Mb}$ of contiguous sequence from chromosome 4 of Arabidopsis thaliana. Nature 391, 485-488. doi: 10.1038/35140

Bianco, L., Lopez, L., Scalone, A. G., Di Carli, M., Desiderio, A., Benvenuto, E., et al. (2009). Strawberry proteome characterization and its regulation during fruit ripening and in different genotypes. J. Proteomics 72, 586-607. doi: 10. 1016/j.jprot.2008.11.019

Buendia, B., Gil, M. I., Tudela, J. A., Gady, A. L., Medina, J. J., Soria, C., et al. (2010). HPLC-MS analysis of proanthocyanidin oligomers and other phenolics in 15 strawberry cultivars. J. Agric. Food Chem. 58, 3916-3926. doi: 10.1021/ jf9030597

Caporale, A. G., Sommella, A., Lorito, M., Lombardi, N., Azam, S. M., Pigna, M., et al. (2014). Trichoderma spp. alleviate phytotoxicity in lettuce plants (Lactuca sativa L.) irrigated with arsenic-contaminated water. J. Plant Physiol. 171, 1378-1384. doi: 10.1016/j.jplph.2014. 05.011

Carbone, F., Preuss, A., De Vos, R. C. H., D’Amico, E., Perrotta, G., Bovy, A. G., et al. (2009). Developmental, genetic and environmental factors affect the expression of flavonoid genes, enzymes and metabolites in strawberry fruits. Plant Cell Environ. 32, 1117-1131. doi: 10.1111/j.1365-3040.2009. 01994

Chacón, M. R., Rodríguez Galán, O., Benítez Fernández, C. T., Sousa, S., Rey, M., Llobell González, A., et al. (2007). Microscopic and transcriptome analyses of early colonization of tomato roots by" Trichoderma harzianum ". Int. Microbiol. 10, 19-27. doi: 10.2436/20.1501.01.4 
Chandra, A., Rana, J., and Li, Y. (2001). Separation, identification, quantification, and method validation of anthocyanins in botanical supplement raw materials by HPLC and HPLC - MS. J. Agric. Food Chem. 49, 3515-3521. doi: 10.1021/ jf010389p

Contreras-Cornejo, H. A., Macías-Rodríguez, L., Beltrán-Peña, E., HerreraEstrella, A., and López-Bucio, J. (2011). Trichoderma-induced plant immunity likely involves both hormonal-and camalexin-dependent mechanisms in Arabidopsis thaliana and confers resistance against necrotrophic fungi Botrytis cinerea. Plant Signal. Behav. 6, 1554-1563. doi: 10.4161/psb.6.10. 17443

da Silva, F. L., Escribano-Bailón, M. T., Alonso, J. J. P., Rivas-Gonzalo, J. C., and Santos-Buelga, C. (2007). Anthocyanin pigments in strawberry. LWT Food Sci. Technol. 40, 374-382. doi: 10.1016/j.lwt.2005. 09.018

D’Ambrosio, C., Arena, S., Rocco, M., Verrillo, F., Novi, G., Viscosi, V., et al. (2013). Proteomic analysis of apricot fruit during ripening. J. Proteomics 78, 39-57. doi: 10.1016/j.jprot.2012.11.008

De Palma, M., D’Agostino, N., Proietti, S., Bertini, L., Lorito, M., Ruocco, M., et al. (2016). Suppression subtractive hybridization analysis provides new insights into the tomato (Solanum lycopersicum L.) response to the plant probiotic microorganism Trichoderma longibrachiatum MK1. J. Plant Physiol. 190, 79-94. doi: 10.1016/j.jplph.2015.11.005

De Palma, M., Salzano, M., Villano, C., Aversano, R., Lorito, M., Ruocco, M., et al. (2019). Transcriptome reprogramming, epigenetic modifications and alternative splicing orchestrate the tomato root response to the beneficial fungus Trichoderma harzianum. Hortic. Res. 6:5. doi: 10.1038/s41438-0180079-1

de Santiago, A., Quintero, J. M., Avilés, M., and Delgado, A. (2011). Effect of Trichoderma asperellum strain T34 on iron, copper, manganese, and zinc uptake by wheat grown on a calcareous medium. Plant Soil 342, 97-104. doi: 10.1007/ s11104-010-0670-1

Figueroa-Balderas, R. E., García-Ponce, B., and Rocha-Sosa, M. (2006). Hormonal and stress induction of the gene encoding common bean acetyl- coenzyme A carboxylase. Plant Physiol. 142, 609-619. doi: 10.1104/pp.106.085597

Fiorentino, N., Ventorino, V., Woo, S. L., Pepe, O., De Rosa, A., Gioia, L., et al. (2018). Trichoderma-based biostimulants modulate rhizosphere microbial populations and improve $\mathrm{N}$ uptake efficiency, yield, and nutritional quality of leafy vegetables. Front. Plant Sci. 9:743. doi: 10.3389/fpls.2018.00743

Freeman, S., Minz, D., Kolesnik, I., Barbul, O., Zveibil, A., Maymon, M., et al. (2004). Trichoderma biocontrol of Colletotrichum acutatum and Botrytis cinerea and survival in strawberry. Eur. J. Plant Pathol. 110, 361-370. doi: 10.1023/b: ejpp.0000021057.93305.d9

Giampieri, F., Tulipani, S., Alvarez-Suarez, J. M., Quiles, J. L., Mezzetti, B., and Battino, M. (2012). The strawberry: composition, nutritional quality, and impact on human health. Nutrition 28, 9-19. doi: 10.1016/j.nut.2011.08.009

Guarino, C., Arena, S., De Simone, L., D’Ambrosio, C., Santoro, S., Rocco, M., et al. (2007). Proteomic analysis of the major soluble components in Annurca apple flesh. Mol. Nutr. Food Res. 51, 255-262. doi: 10.1002/mnfr.20060 0133

Guerreiro, A., Figueiredo, J., Sousa Silva, M., and Figueiredo, A. (2016). Linking jasmonic acid to grapevine resistance against the biotrophic oomycete Plasmopara viticola. Front. Plant Sci. 7:565. doi: 10.3389/fpls.2016.00565

Hanhineva, K., Kärenlampi, S., and Aharoni, A. (2011). Recent advances in strawberry metabolomics. Genomics, transgenics, molecular breeding and biotechnology of strawberry. Genes Genomes Genomics 5, 65-75.

Harman, G. E. (2004). Overview of new insights into mechanisms and uses of Trichoderma based products. Phytopathology 94:138.

Harman, G. E., Howell, C. R., Viterbo, A., Chet, I., and Lorito, M. (2004a). Trichoderma species - opportunistic, avirulent plant symbionts. Nat. Rev. Microbiol. 2, 43-56. doi: 10.1038/nrmicro797

Harman, G. E., Lorito, M., and Lynch, J. M. (2004b). Uses of Trichoderma spp. to alleviate or remediate soil and water pollution. Adv. Appl. Microbiol. 56, 313-330. doi: 10.1016/S0065-2164(04)56010-0

Hepler, P. K. (2005). Calcium: a central regulator of plant growth and development. Plant Cell 17, 2142-2155. doi: 10.1105/tpc.105.032508

Hermosa, R., Viterbo, A., Chet, I., and Monte, E. (2012). Plant-beneficial effects of Trichoderma and of its genes. Microbiology 158, 17-25. doi: 10.1099/mic.0. 052274-0
Holzwarth, M., Korhummel, S., Carle, R., and Kammerer, D. R. (2012). Evaluation of the effects of different freezing and thawing methods on color, polyphenol and ascorbic acid retention in strawberries (Fragaria $\times$ Ananassa Duch.). Food Res. Int. 48, 241-248. doi: 10.1016/j.foodres.2012.04.004

Hsieh, M. H., Lam, H. M., van de Loo, F. J., and Coruzzi, G. A. (1998). PII-like protein in Arabidopsis: putative role in nitrogen sensing. Proc. Natl. Acad. Sci. U.S.A. 95, 13965-13970. doi: 10.1073/pnas.95.23.13965

Joseph, S. V., Edirisinghe, I., and Burton-Freeman, B. M. (2014). Berries: antiinflammatory effects in humans. J. Agric. Food Chem. 62, 3886-3903. doi: 10. 1021/jf4044056

Klefield, O., and Chet, I. (1992). Trichoderma harzianum - interaction with plants and effect on growth response. Plant Soil 144, 267-272. doi: 10.1007/ bf00012884

Li, J., Yang, H., Peer, W. A., Richter, G., Blakeslee, J., Bandyopadhyay, A., et al. (2005). Arabidopsis H+-PPase AVP1 regulates auxin-mediated organ development. Science 310, 121-125. doi: 10.1126/science.1115711

Li, L., Luo, Z., Huang, X., Zhang, L., Zhao, P., Ma, H., et al. (2015). Label-free quantitative proteomics to investigate strawberry fruit proteome changes under controlled atmosphere and low temperature storage. J. Proteomics 120, 44-57. doi: 10.1016/j.jprot.2015.02.016

Li, L., Song, J., Kalt, W., Forney, C., Tsao, R., Pinto, D., et al. (2013). Quantitative proteomic investigation employing stable isotope labeling by peptide dimethylation on proteins of strawberry fruit at different ripening stages. J. Proteomics 94, 219-239. doi: 10.1016/j.jprot.2013.09.004

Liu, S., Manson, J. E., Lee, I. M., Cole, S. R., Hennekens, C. H., Willett, W. C., et al. (2000). Fruit and vegetable intake and risk of cardiovascular disease: the women's health study. Am. J. Clin. Nutr. 72, 922-928. doi: 10.1093/ajcn/72.4. 922

Lombardi, N., Vitale, S., Turrà, D., Reverberi, M., Fanelli, C., Vinale, F., et al. (2018). Root exudates of stressed plants stimulate and attract Trichoderma soil fungi. Mol. Plant Microbe Interact. 31, 982-994. doi: 10.1094/MPMI-12-17-0310-R

Lorito, M., and Woo, S. L. (2015). "Trichoderma: a multi-purpose tool for integrated pest management," in Principles of Plant-Microbe Interactions, ed. B. Lugtenberg (Cham: Springer), 345-353. doi: 10.1007/978-3-319-08575-3_36

Lorito, M., Woo, S. L., Harman, G. E., and Monte, E. (2010). Translational research on Trichoderma: from 'omics to the field. Annu. Rev. Phytopathol. 48, 395-417. doi: 10.1146/annurev-phyto-073009-114314

Määttä-Riihinen, K. R., Kamal-Eldin, A., and Törrönen, A. R. (2004). Identification and quantification of phenolic compounds in berries of Fragaria and Rubus species (family Rosaceae). J. Agric. Food Chem. 52, 6178-6187. doi: 10.1021/ jf049450r

Manganiello, G., Sacco, A., Ercolano, M. R., Vinale, F., Lanzuise, S., Pascale, A., et al. (2018). Modulation of tomato response to Rhizoctonia solani by Trichoderma harzianum and its secondary metabolite harzianic acid. Front. Microbiol. 9:1966. doi: 10.3389/fmicb.2018.01966

Marra, R., Ambrosino, P., Carbone, V., Vinale, F., Woo, S. L., Ruocco, M., et al. (2006). Study of the three-way interaction between Trichoderma atroviride, plant and fungal pathogens by using a proteomic approach. Curr. Genet. 50, 307-321. doi: 10.1007/s00294-006-0091-0

Marra, R., Lombardi, N., d'Errico, G., Troisi, J., Scala, G., Vinale, F., et al. (2019). Application of Trichoderma strains and metabolites enhances soybean productivity and nutrient content. J. Agric. Food Chem. 67, 1814-1822. doi: 10.1021/acs.jafc.8b06503

Mastouri, F., Björkman, T., and Harman, G. E. (2012). Trichoderma harzianum enhances antioxidant defense of tomato seedlings and resistance to water deficit. Mol. Plant Microbe Interact. 25, 1264-1271. doi: 10.1094/MPMI-09-110240

Mathys, J., De Cremer, K., Timmermans, P., Van Kerkhove, S., Lievens, B., Vanhaecke, M., et al. (2012). Genome-wide characterization of ISR induced in Arabidopsis thaliana by Trichoderma hamatum T382 against Botrytis cinerea infection. Front. Plant Sci. 3:108. doi: 10.3389/fpls.2012.00108

Molassiotis, A., Tanou, G., Filippou, P., and Fotopoulos, V. (2013). Proteomics in the fruit tree science arena: new insights into fruit defense, development, and ripening. Proteomics 13, 1871-1884. doi: 10.1002/pmic.201200428

Navazio, L., Moscatiello, R., Genre, A., Novero, M., Baldan, B., Bonfante, P., et al. (2007). A diffusible signal from arbuscular mycorrhizal fungi elicits a transient cytosolic calcium elevation in host plant cells. Plant Physiol. 144, 673-681. doi: $10.1104 /$ pp.106.086959 
Nogueira-Lopez, G., Greenwood, D. R., Middleditch, M., Winefield, C., Eaton, C., Steyaert, J. M., et al. (2018). The apoplastic secretome of Trichoderma virens during interaction with maize roots shows an inhibition of plant defence and scavenging oxidative stress secreted proteins. Front. Plant. Sci. 9:409. doi: 10. 3389/fpls.2018.00409

Ousley, M. A., Lynch, J. M., and Whipps, J. M. (1994). Potential of Trichoderma spp. as consistent plant growth stimulators. Biol. Fertil. Soils 17, 85-90. doi: 10.1007/bf00337738

Palmieri, M. C., Perazzolli, M., Matafora, V., Moretto, M., Bachi, A., and Pertot, I. (2012). Proteomic analysis of grapevine resistance induced by Trichoderma harzianum T39 reveals specific defence pathways activated against downy mildew. J. Exp. Bot. 63, 6237-6251. doi: 10.1093/jxb/ers279

Park, D., Park, Y., Lee, Y. H., Choi, I. Y., Park, K. C., Park, S. U., et al. (2017). A comparative study of phenolic antioxidant activity and flavonoid biosynthesis related gene expression between summer and winter strawberry cultivars. J. Food Sci. 82, 341-349. doi: 10.1111/1750-3841.13600

Pascale, A., Vinale, F., Manganiello, G., Nigro, M., Lanzuise, S., Ruocco, M., et al. (2017). Trichoderma and its secondary metabolites improve yield and quality of grapes. Crop Prot. 92, 176-181. doi: 10.1016/j.cropro.2016.11.010

Pecenková, T., Markovic, V., Sabol, P., Kulich, I., and Žársk $\iota$, V. (2017). Exocyst and autophagy-related membrane trafficking in plants. J. Exp. Bot. 69, 47-57. doi: 10.1093/jxb/erx363

Perazzolli, M., Palmieri, M. C., Matafora, V., Bachi, A., and Pertot, I. (2016). Phosphoproteomic analysis of induced resistance reveals activation of signal transduction processes by beneficial and pathogenic interaction in grapevine. J. Plant Physiol. 195, 59-72. doi: 10.1016/j.jplph.2016.03.007

Pérez, A. C., and Goossens, A. (2013). Jasmonate signalling: A copycat of auxin signalling? Plant Cell Environ. 36, 2071-2084. doi: 10.1111/pce.12121

Porras, M., Barrau, C., Arroyo, F. T., Santos, B., Blanco, C., and Romero, F. (2007). Reduction of Phytophthora cactorum in strawberry fields by Trichoderma spp. and soil solarization. Plant Dis. 91, 142-146. doi: 10.1094/PDIS-91-2-0142

Ramirez, R. G., Haelein, T. A., Reyna, J., McDowell, L. R., Russel, L., Aganga, A. A., et al. (1996). Association of official analytical chemists. Official methods of analysis. J. Biol. Sci. 5, 7-16.

Rubio, M. B., Hermosa, R., Vicente, R., Gómez-Acosta, F. A., Morcuende, R., Monte, E., et al. (2017). The combination of Trichoderma harzianum and chemical fertilization leads to the deregulation of phytohormone networking, preventing the adaptive responses of tomato plants to salt stress. Front. Plant Sci. 8:294. doi: 10.3389/fpls.2017.00294

Salzano, A. M., Renzone, G., Sobolev, A. P., Carbone, V., Petriccione, M., Capitani, D., et al. (2019). Unveiling Kiwifruit metabolite and protein changes in the course of postharvest cold storage. Front. Plant Sci. 4:71. doi: 10.3389/fpls.2019. 00071

Salzano, A. M., Sobolev, A., Carbone, V., Petriccione, M., Renzone, G., Capitani, D., et al. (2018). A proteometabolomic study of Actinidia deliciosa fruit development. J. Proteomics 172, 11-24. doi: 10.1016/j.jprot.2017.11.004

Schilling, R. K., Marschner, P., Shavrukov, Y., Berger, B., Tester, M., Roy, S. J., et al. (2014). Expression of the Arabidopsis vacuolar $\mathrm{H}^{+}$-pyrophosphatase gene (AVP1) improves the shoot biomass of transgenic barley and increases grain yield in a saline field. Plant Biotechnol. J. 12, 378-386. doi: 10.1111/pbi. 12145

Segarra, G., Casanova, E., Bellido, D., Odena, M. A., Oliveira, E., and Trillas, I. (2007). Proteome, salicylic acid, and jasmonic acid changes in cucumber plants inoculated with Trichoderma asperellum strain T34. Proteomics 7, 3943-3952. doi: 10.1002/pmic.200700173

Senthil-Kumar, M., and Mysore, K. S. (2010). Assessing functional role of three water deficit stress-induced genes in nonhost disease resistance using virusinduced gene silencing in Nicotiana benthamiana. Plant Signal. Behav. 5, 586-590. doi: 10.4161/psb.11497

Sharma, E., Anand, G., and Kapoor, R. (2017). Terpenoids in plant and arbuscular mycorrhiza-reinforced defence against herbivorous insects. Ann. Bot. 119, 791-801. doi: 10.1093/aob/mcw263

Sharma, O. P., and Bhat, T. K. (2009). DPPH antioxidant assay revisited. Food Chem. 113, 1202-1205. doi: 10.1016/j.foodchem.2008.08.008

Shoresh, M., and Harman, G. E. (2008). The molecular basis of shoot responses of maize seedlings to Trichoderma harzianum T22 inoculation of the root: a proteomic approach. Plant Physiol. 147, 2147-2163. doi: 10.1104/pp.108. 123810
Shoresh, M., Harman, G. E., and Mastouri, F. (2010). Induced systemic resistance and plant responses to fungal biocontrol agents. Annu. Rev. Phytopathol. 48, 21-43. doi: 10.1146/annurev-phyto-073009-114450

Singh, U. B., Malviya, D., Khan, W., Singh, S., Karthikeyan, N., Imran, M., et al. (2018). Earthworm grazed-Trichoderma harzianum biofortified spent mushroom substrates modulate accumulation of natural antioxidants and biofortification of mineral nutrients in tomato. Front. Plant Sci. 9:1017. doi: 10. 3389/fpls.2018.01017

Singleton, V. L., Orthofer, R., and Lamuela-Raventós, R. M. (1998). Analysis of total phenols and other oxidation substrates and antioxidants by means of folinciocalteu reagent. Methods Enzymol. 5, 759-766. doi: 10.1016/S0076-6879(99) 99017-1

Sturn, A., Quackenbush, J., and Trajanoski, Z. (2002). Genesis: cluster analysis of microarray data. Bioinformatics 18, 207-208. doi: 10.1093/bioinformatics/18.1. 207

Tronsmo, A., and Dennis, C. (1977). The use of Trichoderma species to control strawberry fruit rots. Netherlands J. Plant Pathol. 83:449. doi: 10.1007/ bf03041462

Tucci, M., Ruocco, M., De Masi, L., De Palma, M., and Lorito, M. (2011). The beneficial effect of Trichoderma spp. on tomato is modulated by the plant genotype. Mol. Plant Pathol. 12, 341-354. doi: 10.1111/J.1364-3703.2010. 00674.X

Uhrig, R. G., Ng, K. K., and Moorhead, G. B. (2009). PII in higher plants: a modern role for an ancient protein. Trends Plant Sci. 14, 505-511. doi: 10.1016/j.tplants. 2009.07.003

Valentinuzzi, F., Pii, Y., Vigani, G., Lehmann, M., Cesco, S., and Mimmo, T. (2015). Phosphorus and iron deficiencies induce a metabolic reprogramming and affect the exudation traits of the woody plant Fragaria $\times$ ananassa. J. Exp. Bot. 66, 6483-6495. doi: 10.1093/jxb/erv364

Vinale, F., Sivasithamparam, K., Ghisalberti, E. L., Marra, R., Woo, S. L., and Lorito, M. (2008). Trichoderma-plant-pathogen interactions. Soil Biol. Biochem. 40, 1-10. doi: 10.1016/j.soilbio.2007.07.002

Vinale, F., Sivasithamparam, K., Ghisalberti, E. L., Ruocco, M., Woo, S., and Lorito, M. (2012). Trichoderma secondary metabolites that affect plant metabolism. Nat. Prod. Commun. 7, 1545-1550. doi: 10.1177/1934578X1200701133

Vinale, F., Sivasithamparam, K., Ghisalberti, E. L., Woo, S. L., Nigro, M., Marra, R., et al. (2014). Trichoderma secondary metabolites active on plants and fungal pathogens. Open Mycol. J. 8, 127-139. doi: 10.2174/1874437001408010127

Vitha, S., McAndrew, R. S., and Osteryoung, K. W. (2001). FtsZ ring formation at the chloroplast division site in plants. J. Cell Biol. 153, 111-120. doi: 10.1083/ jcb.153.1.111

Vitti, A., La Monaca, E., Sofo, A., Scopa, A., Cuypers, A., and Nuzzaci, M. (2015). Beneficial effects of Trichoderma harzianum T-22 in tomato seedlings infected by Cucumber mosaic virus (CMV). BioControl 60, 135-147. doi: 10.1007/ s10526-014-9626-3

Vizcaíno, J. A., Csordas, A., del-Toro, N., Dianes, J. A., Griss, J., Lavidas, I., et al. (2016). Update of the PRIDE database and its related tools. Nucleic Acids Res. 44, 447-456. doi: 10.1093/nar/gkw880

Wang, M., Ding, L., Gao, L., Li, Y., Shen, Q., and Guo, S. (2016). The interactions of aquaporins and mineral nutrients in higher plants. Int. J. Mol. Sci. 17:1229. doi: 10.3390/ijms17081229

Woo, S. L., and Pepe, O. (2018). Microbial consortia: promising probiotics as plant biostimulants for sustainable agriculture. Front. Plant Sci. 9:1801. doi: 10.3389/fpls.2018.01801

Woo, S. L., Ruocco, M., Vinale, F., Nigro, M., Marra, R., Lombardi, N., et al. (2014). Trichoderma-based products and their widespread use in agricolture. Open Mycol. J. 8, 71-126. doi: 10.3389/fpls.2018.01801

Yang, H., Zhang, X., Gaxiola, R. A., Xu, G., Peer, W. A., and Murphy, A. S. (2014). Over-expression of the Arabidopsis proton-pyrophosphatase AVP1 enhances transplant survival, root mass, and fruit development under limiting phosphorus conditions. J. Exp. Bot. 65, 3045-3053. doi: 10.1093/jxb/eru149

Yedidia, I., Benhamou, N., Kapulnik, Y., and Chet, I. (2000). Induction and accumulation of PR proteins activity during early stages of root colonization by the mycoparasite Trichoderma harzianum strain T-203. Plant Physiol. Biochem. 38, 863-873. doi: 10.1016/s0981-9428(00)01198-0

Yedidia, I., Shoresh, M., Kerem, Z., Benhamou, N., Kapulnik, Y., and Chet, I. (2003). Concomitant induction of systemic resistance to Pseudomonas syringae pv. lachrymans in cucumber by Trichoderma asperellum (T-203) and 
accumulation of phytoalexins. Appl. Environ. Microbiol. 69, 7343-7353. doi: 10.1128/AEM.69.12.7343-7353.2003

Yedidia, I., Srivastva, A. K., Kapulnik, Y., and Chet, I. (2001). Effect of Trichoderma harzianum on microelement concentrations and increased growth of cucumber plants. Plant Soil 235, 235-242.

Yu, M. H., Zhao, Z. Z., and He, J. X. (2018). Brassinosteroid signaling in plant-microbe interactions. Int. J. Mol. Sci. 19:4091. doi: 10.3390/ijms1912 4091

Yuan, P., Jauregui, E., Du, L., Tanaka, K., and Poovaiah, B. W. (2017). Calcium signatures and signaling events orchestrate plant-microbe interactions. Curr. Opin. Plant Biol. 38, 173-183. doi: 10.1016/j.pbi.2017.06.003

Yun, H. S., and Kwon, C. (2017). Vesicle trafficking in plant immunity. Curr. Opin. Plant Biol. 40, 34-42. doi: 10.1016/j.pbi.2017.07.001

Zhang, F., Chen, C., Zhang, F., Gao, L., Liu, J., Chen, L., et al. (2017). Trichoderma harzianum containing 1-aminocyclopropane-1-carboxylate deaminase and chitinase improved growth and diminished adverse effect caused by Fusarium oxysporum in soybean. J. Plant Physiol. 210, 84-94. doi: 10.1016/j.jplph.2016. 10.012

Conflict of Interest: The authors declare that the research was conducted in the absence of any commercial or financial relationships that could be construed as a potential conflict of interest.

Copyright (c) 2020 Lombardi, Caira, Troise, Scaloni, Vitaglione, Vinale, Marra, Salzano, Lorito and Woo. This is an open-access article distributed under the terms of the Creative Commons Attribution License (CC BY). The use, distribution or reproduction in other forums is permitted, provided the original author(s) and the copyright owner(s) are credited and that the original publication in this journal is cited, in accordance with accepted academic practice. No use, distribution or reproduction is permitted which does not comply with these terms. 